Revista Española de Derecho Internacional Sección JURISPRUDENCIA DIPub Vol. 68/1, enero-junio 2016, Madrid, pp. 165-218 http://dx.doi.org/10.17103/redi.68.1.2016.3b

(C) 2016 Asociación de Profesores de Derecho Internacional y Relaciones Internacionales ISSN: 0034-9380; E-ISSN: 2387-1253

\title{
B) JURISPRUDENCIA ESPAÑOLA Y EUROPEA DE DERECHO INTERNACIONAL PRIVADO *
}

\author{
Selección y coordinación a cargo de \\ Santiago ÁlvAREZ GoNZÁLEZ
}

Catedrático de Derecho internacional privado Universidad de Santiago de Compostela

SUMARIO: 1. TRIBUNAL DE JUSTICIA: ESPACIO DE LIBERTAD, SEGURIDAD Y JUSTICIA.1.1. Competencia judicial internacional: insolvencia.-1.2. Competencia judicial internacional. Reglamento 44/2001.-1.3. Competencia judicial internacional: Reglamento 2201/2003.1.4. Competencia judicial internacional: Reglamento 4/2009.-1.5. Reconocimiento y ejecución de resoluciones: Reglamento 2201/2003.-1.6. Ley aplicable: Reglamento Roma II.-2. PRÁCTICA ESPAÑOLA: DERECHO JUDICIAL INTERNACIONAL.-2.1. Competencia judicial internacional: Reglamento 44/2001.-2.2. Competencia judicial internacional: Reglamento 2201/2003.—2.3. Reconocimiento y ejecución de resoluciones extranjeras.-3. PRÁCTICA ESPAÑOLA: DERECHO CIVIL INTERNACIONAL.-3.1. Determinación de la ley aplicable: filiación natural.-3.2. Determinación de la ley aplicable: Versorgungsausgleich.-3.3. Determinación de la ley aplicable: cesión de créditos.-3.4. Determinación de la ley aplicable: sucesión por causa de muerte.

* Esta crónica es continuación de la publicada en REDI, 2015-2. La selección se ha efectuado sobre resoluciones dictadas durante el año 2015. Colaboran en la presente crónica, Santiago Álvarez González, Laura Carballo Piñeiro, Clara Isabel Cordero Álvarez, Lydia Esteve González, Josep María Fontanellas Morell, Ángel Espiniella Menéndez, Carmen María García Mirete, Cristina González Beilfuss, Mónica Guzmán Zapater, Lerdys S. Heredia Sánchez, Raúl Lafuente Sánchez, Nerea Magallón Elósegui, Javier Maseda Rodríguez, Pedro A. de Miguel Asensio, Patricia Orejudo Prieto de los Mozos y Alfonso Ortega Giménez, de las Universidades de Alicante, Barcelona, Complutense de Madrid, Deusto, Miguel Hernández, Lleida, Oviedo, Santiago de Compostela y UNED. Es esta la última crónica con el presente formato y el presente coordinador, por lo que desde aquí me permito la licencia de un obligado agradecimiento a los casi 90 colaboradores de más de 25 universidades españolas y centros de investigación extranjeros que la han hecho posible durante los últimos quince años. Muchas gracias. 


\section{TRIBUNAL DE JUSTICIA: ESPACIO DE LIBERTAD, SEGURIDAD Y JUSTICIA}

\subsection{Competencia judicial internacional: insolvencia}

2016-1-Pr

COMPETENCIA JUDICIAL INTERNACIONAL.-Procedimiento principal de insolvencia.-Procedimiento secundario de insolvencia.-Conflicto de competencias.-Competencia alternativa.-Bienes afectados por el procedimiento secundario.-Localización.-_Venta global de activos.

Preceptos aplicados: arts. 3, apartado 2, y 27 del Reglamento (CE) núm. 1346/2000.

Sentencia del TJUE (Sala 1..$^{a}$ ), de 11 de junio de 2015, asunto C-649/13, Comité d'entreprise de Nortel Networks SA y otros c. A. R. Bloom y otros. Ponente: Sra. M. Berger.

F.: curia.europa.eu.

\section{[...] En virtud de todo lo expuesto, el Tribunal de Justicia (Sala 1. ${ }^{a}$ ) declara:}

Los artículos 3, apartado 2, y 27 del Reglamento (CE) no 1346/2000 del Consejo, de 29 de mayo de 2000, sobre procedimientos de insolvencia, deben interpretarse en el sentido de que los tribunales del Estado miembro en el que se ha abierto un procedimiento secundario de insolvencia son competentes, con carácter alternativo a los tribunales del Estado miembro en el que se ha abierto el procedimiento principal, para determinar los bienes del deudor sujetos a los efectos de ese procedimiento secundario.

La determinación de los bienes del deudor sujetos a los efectos de un procedimiento secundario de insolvencia debe realizarse conforme a las disposiciones del artículo 2, letra g), del Reglamento $n^{\circ} 1346 / 2000$.

Nota. 1. Un grupo multinacional de sociedades, Nortel, tiene abiertos distintos procedimientos de insolvencia en Canadá, Estados Unidos y Reino Unido. Para una mejor gestión de la crisis empresarial, se aprueba una venta global de activos y el depósito de los ingresos en unas cuentas bancarias en Estados Unidos, bloqueadas hasta que exista un acuerdo sobre el porcentaje de reparto entre los distintos concursos. Ocurre que sobre una de las sociedades filiales del grupo, concursada en el Reino Unido, se abre un procedimiento secundario en Francia, en el marco del cual el comité de empresa y antiguos empleados presentan una acción para que les sea reconocido el derecho sobre la parte proporcional de los ingresos existentes en las cuentas bloqueadas.

A estos efectos, resulta aplicable el Reglamento (CE) núm. 1346/2000, de 20 de mayo, sobre procedimientos de insolvencia, pues el eventual derecho de los trabajadores está estrechamente vinculado al procedimiento de insolvencia y se fundamenta en la legislación concursal (apdo. 30), o mejor dicho, en los acuerdos de enajenación y liquidación alcanzados por los administradores concursales. En consecuencia, los tribunales del Estado donde se ha abierto el procedimiento secundario tienen competencia para conocer de las acciones conexas que se refieran a los bienes de la masa secundaria. Dicha masa abarca los bienes que se hallen en el Estado de apertura, de conformidad con las reglas de localización de bienes del propio Reglamento, a 
saber: los derechos inmateriales registrados en el Estado de apertura y los créditos del concursado contra deudores cuyo centro de intereses esté en ese mismo Estado de apertura. La interpretación del Tribunal resulta en este punto acertada. Desde una perspectiva sistemática, la referencia a las acciones conexas contenidas en el art. 25 del Reglamento se predica tanto del procedimiento principal como del procedimiento territorial (apdos. 34 y 35 de la sentencia). Aunque se trata de un precepto relativo al reconocimiento de decisiones, debe interpretarse en paralelo a la competencia judicial internacional del tribunal que conoce de un concurso territorial. Desde una perspectiva finalista, los procedimientos secundarios no solo buscan auxiliar al procedimiento principal, sino que también pretenden proteger las expectativas de los acreedores locales (apdos. 36 y 37). Son, en este sentido, procedimientos plenos (full proceedings en terminología inglesa bastante ilustrativa), con el mismo contenido que un procedimiento principal, salvo que se predican de los bienes localizados en el Estado de apertura. Efectivamente, los bienes ubicados en otros países según las normas del Reglamento quedan fuera del ámbito del concurso territorial, con lo que ya es irrelevante si se encuentran en Estados miembros o en terceros países, como bien destaca el Tribunal.

2. A pesar de lo expuesto, la cuestión más polémica de la sentencia es la articulación de una competencia alternativa entre los tribunales del procedimiento principal y los tribunales del procedimiento secundario para este tipo de acciones conexas de determinación de la masa secundaria, basada en el efecto útil del Reglamento europeo de insolvencia (apdo. 41). Se trata de una solución salomónica: la competencia del juez del concurso territorial se justifica porque dicho órgano está determinando la masa activa de este concurso (competencia para la inclusión de bienes en la masa secundaria); la competencia del juez del concurso principal se justifica porque este ve excluidos ciertos bienes de su propia masa (competencia para la exclusión de bienes de la masa principal). Esta interpretación plantea dudas con carácter general, como parece formularla el Tribunal, pero también con carácter singular para la acción tan peculiar ejercitada. Con carácter general, se aprecian omisiones e imprecisiones. Así, el Tribunal no aborda el problema de que, al margen de normas materiales y conflictuales uniformes, cada tribunal aplica su propia ley (lex fori concursus), con lo que una competencia alternativa puede derivar de forma poco justificada en una ley aplicable alternativa. Destaca, también, el silencio del Tribunal sobre la posible litispendencia o conexidad ante los dos tribunales, respecto de las cuales el Reglamento europeo de insolvencia no dispone nada y que podrían ser muy habituales a partir de este fallo. Piénsese, por ejemplo, en el ejercicio ante el tribunal del concurso principal de una acción para la exclusión de bienes de su masa, al tiempo que en el procedimiento territorial se insta la inclusión en el inventario de tales bienes.

Además de omisiones, se observan imprecisiones. El juez de cada concurso es exclusivamente competente para determinar la inclusión de bienes en cada una de sus masas conforme a su propia ley (y a salvo de las normas uniformes del Reglamento). Se trata de una cuestión esencial del desarrollo de un procedimiento de insolvencia que solo puede ser resuelta por el juez que está tramitando ese concurso. Que ello influya en disminuir las masas de otros concursos es un efecto colateral que no puede poner a esos otros tribunales en igual posición que al juez del concurso. Especialmente dudoso resulta el Tribunal en su apartado 42, cuando declara que la competencia alternativa del tribunal del procedimiento principal se justifica porque este también es competente para conocer de las acciones conexas. Oculta el Tribunal que la competencia de los tribunales del procedimiento principal está pensada para acciones 
conexas vinculadas a la masa principal, pero no para acciones vinculadas a la masa territorial, que es distinta y tiene autonomía propia.

3. Si como solución general esta interpretación no es del todo convincente, tampoco lo es para casos excepcionales como el de este asunto, referidos a la consolidación de activos o ingresos obtenidos por su enajenación. En estos supuestos, la competencia alternativa debería haber sido sustituida por una competencia cumulativa. Los tribunales de todos los concursos deben aprobar $\mathrm{u}$ homologar los porcentajes de distribución de los ingresos, porque todos y cada uno de ellos han consentido en la enajenación conjunta y en la consolidación de activos. Así es como este tipo de operaciones mejor ha funcionado en la práctica comparada (véase EsPINIELLA MENÉNDEZ, A., Procedimientos de insolvencia y grupos multinacionales de sociedades, Cizur Menor, Thomson/Civitas, 2006, p. 178). En el supuesto de que no se obtuviera la homologación de los porcentajes de distribución en todos los concursos, no debería hacerse la consolidación de activos y cada uno de los concursos debería llevar a la masa los que les pertenecieran y sobre los que tuviera posibilidad real de apoderamiento.

En el caso que nos ocupa, debe tenerse en cuenta, además, que el concurso territorial se refiere a un establecimiento o sucursal de una sociedad filial y no a la sociedad filial en sí misma considerada. De hecho, lo deseable para una cooperación eficaz sería establecer dos niveles de negociación por parte de las administraciones concursales: en un primer nivel, deben negociarse los porcentajes de reparto de activos del grupo respecto de cada sociedad miembro y ello corresponde prioritariamente a la administración del concurso principal de cada sociedad. Una vez fijada la cuota que corresponde a la sociedad concursada, y ya respecto de esta, en un segundo nivel, puede distinguirse qué porcentaje corresponde a su concurso principal y cuál al concurso territorial. Por ejemplo, la sociedad concursada puede tener derecho a 100.000 euros de un total de 1.000.000 de euros de activos del grupo, aspecto que negociaría la administración del concurso principal de esa sociedad. En un segundo momento, ya cabría negociar qué parte de esos 100.000 euros es para el concurso principal y cuál para el concurso territorial.

4. Si la sentencia plantea algunas dudas, sería injusto imputárselas exclusivamente al Tribunal de Justicia, pues el caso muestra cinco déficits estructurales del Reglamento europeo de insolvencia. En primer lugar, el Reglamento no da pauta alguna sobre la praxis de las administraciones concursales en casos de confusión de patrimonios o consolidaciones sustantivas de activos. Es recomendable que, a diferencia del caso concreto, los eventuales acuerdos de coordinación de procedimientos o de consolidación de activos regulen ab initio cuestiones básicas y esenciales, como el porcentaje que cada concurso recibirá de los ingresos totales, para evitar un bloqueo posterior del reparto por falta de acuerdo. En segundo lugar, la controversia surge en realidad por una situación anómala que ampara el Reglamento: la posibilidad de que se abra un procedimiento secundario a una sociedad filial (en el caso, Francia) que puede llegar a vaciar de activos y contenido al concurso principal abierto a esta en otro Estado (en el caso, Reino Unido). Ello ocurre si se abre un concurso territorial donde está el principal establecimiento de la filial, que se administra habitualmente desde otro Estado. Además, y en tercer lugar, si ya de por sí es compleja la crisis empresarial de distintas sociedades de un grupo multinacional, las dificultades aumentan notablemente si a su vez esas sociedades tienen sucursales y establecimientos secundarios en otros Estados y aparecen varios concursos territoriales. En cuarto lugar, las normas de localización de bienes del Reglamento, a las que recurre el Tribunal como solución «sencilla» para determinar la masa secundaria, no 
son suficientes para decidir los porcentajes de reparto de los ingresos cuando, precisamente, los bienes se han enajenado en su conjunto por un precio global superior a su venta por separado. No se trata solo de determinar qué bienes pertenecen a un concurso territorial, sino de resolver qué porcentaje de los ingresos corresponden a cada concurso, y ambas cuestiones no son exactamente sinónimas. En quinto lugar, y ya trascendiendo al caso concreto, la competencia del juez de un concurso territorial para conocer de acciones conexas, que claramente se deduce del Reglamento y que por primera vez reconoce el Tribunal de Justicia en varios pasajes de esta sentencia, puede generar nuevas incertidumbres. Piénsese, por ejemplo, en la posibilidad de ejercitar múltiples acciones de responsabilidad de los administradores societarios por la insolvencia de la sociedad.

\author{
Ángel EsPiniella MENÉNDEZ \\ Universidad de Oviedo \\ http://dx.doi.org/10.17103/redi.68.1.2016.3b.01
}

2016-2-Pr

LEY APLICABLE A LAS ACCIONES REVOCATORIAS CONCURSALES.-Delimitación del alcance de la excepción a la lex fori concursus. Carga de la prueba.

Preceptos aplicados: arts. 4 y 13 del Reglamento (CE) núm. 1346/2000, sobre procedimientos de insolvencia.

Sentencia del TJUE (Sala 6. ${ }^{\mathrm{a}}$ ), de 15 de octubre de 2015, asunto C-310/14, Nike European Operations Netherlands BV y Sportland Oy, en liquidación. Ponente: M. Berger.

\title{
F: curia.europa.eu.
}

1) El art. 13 del Reglamento (CE) núm. 1346/2000 del Consejo, de 29 de mayo, sobre procedimientos de insolvencia, debe interpretarse en el sentido de que su aplicación está sujeta al requisito de que el acto de que se trate no pueda ser impugnado sobre la base de la ley aplicable a dicho acto (lex causae), habida cuenta de todas las circunstancias del caso concreto.

2) Para aplicar el art. 13 del Reglamento núm. 1346/2000, y en el supuesto en que el demandado en una acción de nulidad, de anulación o de inoponibilidad de un acto invoque una disposición de la ley aplicable a dicho acto (lex causae) según la cual este acto solo es impugnable en las circunstancias previstas por dicha disposición, incumbe a dicho demandado alegar la inexistencia de estas circunstancias y aportar prueba de ello.

3) El art. 13 del Reglamento núm. 1346/2000 debe interpretarse en el sentido de que la expresión "no permite en ningún caso que se impugne dicho acto" se refiere, además de a las disposiciones de la ley aplicable a dicho acto (lex causae) aplicables en materia de insolvencia, a todas las disposiciones y principios generales de esta ley.

4) El art. 13 del Reglamento núm. 1346/2000 debe interpretarse en el sentido de que el demandado en una acción de nulidad, de anulación o de inoponibilidad de un acto debe demostrar que la ley aplicable a dicho acto (lex causae), en su conjunto, no permite impugnar dicho acto. El tribunal nacional que conoce de tal acción solo puede considerar que incumbe al demandante aportar prueba de la existencia de una disposición o 
de un principio de esta ley en virtud de los cuales este acto puede impugnarse cuando dicho tribunal considera que el demandado, en un primer momento, ha demostrado efectivamente, a la luz de las reglas habitualmente aplicables según su Derecho procesal nacional, que el acto de que se trata es inimpugnable en virtud de la misma ley.

Nota. 1. A pesar de que unas de las acciones más utilizadas en los procedimientos de insolvencia son las revocatorias concursales, los casos internacionales son escasos, también en el seno del espacio europeo de justicia. Ello ya llevó al Parlamento Europeo en 2011 a sugerir la revisión del art. 13 del Reglamento (CE) 1346/2000, de 29 de mayo, sobre procedimientos de insolvencia (RI) [2011/2006(INI)], dado que este precepto es un obstáculo a su éxito, puesto que obliga a tomar en consideración dos reglamentaciones distintas de la acción revocatoria, la de la ley rectora del concurso y la del acto impugnado, de manera que conseguir que prospere en un supuesto internacional es significativamente más complicado que en uno doméstico. El Tribunal de Justicia solo se ha pronunciado sobre este precepto en dos sentencias de 2015, siendo la primera de 16 de abril, asunto C-557/13, Hermann Lutz v. Elke Bäuerle (REDI 2015-28-Pr). La segunda es la que aquí se comenta, de 15 de octubre, y versa sobre la impugnación de los pagos hechos en el marco de un contrato de distribución regido por la ley holandesa entre Sportland, sociedad finlandesa, y Nike, sociedad holandesa. Cuando Sportland deviene judicialmente insolvente, la administración concursal busca la revocación de los pagos hechos a Nike de acuerdo con la ley concursal finlandesa, a lo que se opone la empresa holandesa indicando que la revocatoria concursal no puede prosperar ya que no cumple los requisitos dispuestos para ello por la ley holandesa, oposición a la operatividad de la ley concursal permitida por el citado art. 13. A continuación, se explica la lógica detrás de esta norma y los problemas que suscita a la luz de la decisión comentada, en tanto que luego se examina lo característico de esta decisión respecto a Lutz, la explicitación de cuál es el reparto de la carga de la prueba de acuerdo con este precepto.

2. A la hora de evaluar el art. 13 ha de tenerse en cuenta que estas acciones sirven a objetivos concursales, como indicaba el Tribunal de Justicia en su decisión de 12 de febrero de 2009, asunto C-339/07, Seagon v. Deko Marty Belgium, donde se explicita que es una acción que deriva directamente del procedimiento de insolvencia y guarda una estrecha vinculación con este. Esta doctrina ha pasado al art. 6.1 del Reglamento (UE) 2015/848, de 20 de mayo — cuyas normas se aplicarán a los concursos que se abran en un Estado miembro a partir del 26 de junio de 2017-que se refiere a las acciones revocatorias como un caso de vis attractiva concursus internacional. En la misma línea, los arts. 4.2.m) RI y 7.2.m) del Reglamento 2015/848 someten el ejercicio de las mismas a la lex fori concursus y, sin embargo, por mor de las expectativas de terceros y la seguridad del tráfico, el citado art. 13.16 del nuevo Reglamento, permite que el tercero beneficiado por el acto impugnado impida el éxito de la acción revocatoria arguyendo que el mismo se somete a una ley distinta y esta no permite que se impugne por medio alguno en el caso concreto. El resultado es una regla que hace depender el éxito de la revocatoria de dos leyes con las consecuentes dificultades para una acción que sirve a objetivos concursales y, en general, a evitar el perjuicio de acreedores. Es por ello que el Tribunal de Justicia puntualiza que la interpretación del art. 13 ha de ser estricta y en línea con el objetivo que lo preside, proteger las expectativas de terceros (asuntos C-557/13, apdo. 34; C-310/14, apdo. 18).

Esta interpretación estricta afecta, en particular, al ámbito de aplicación del precepto y a las obligaciones que pesan a quien se beneficia del mismo, el tercero demandado en la acción revocatoria. El precepto analizado constituye una excepción 
a la aplicación de la lex fori concursus, de ahí que solo pueda utilizarse en aquellos supuestos en los que el acto impugnado es anterior a la apertura del concurso; si es posterior, se aplica solo la ley concursal a su revocación dado que no hay expectativas de terceros que proteger. Esta es la conclusión a la que llega el Tribunal de Justicia en Lutz donde se permite utilizar el art. 13 para evitar la ineficacia frente a la masa concursal de un pago realizado en el marco de un embargo constituido antes de la apertura del procedimiento de insolvencia (asunto C-557/13, apdo. 42). Nike acaba de perfilar cómo opera el art. 13, esto es, corresponde al tercero beneficiado por el acto impugnado alegar y probar que el mismo se rige por una ley distinta de la concursal y que esta no permite su impugnación en caso alguno.

3. La carga de la prueba recae, por tanto, en el tercero beneficiado por el acto impugnado, dato que acentúa Nike para evitar que se realicen inversiones de la carga sin tener en cuenta la interpretación estricta del art. 13. Con ello se evita que el administrador concursal se vea obligado a discutir en dos derechos, salvo cuando es absolutamente imprescindible. Así, el demandado ha de demostrar que el acto se somete a una ley distinta de la concursal, es decir, ha de solventar el conflicto de leyes de acuerdo con el instrumento que corresponda y probar el Derecho extranjero, incluso en aquellos países en los que el juez sea normalmente el encargado de esta prueba. Y ha de probar que el acto no es impugnable de acuerdo con esta ley, precisando Nike que el tercero no puede limitarse a indicar que el acto es inatacable, es decir, la alegación no puede quedarse en un plano abstracto, sino que el demandado ha de descender a los detalles del caso para, a la luz de las circunstancias concretas, demostrar que así es (asunto C-310/14, apdo. 25). Además, la prueba no solo alcanza a las normas concursales de la lex causae y cómo configura esta las acciones revocatorias concursales, sino también a cualquier otro medio de impugnación previsto por las disposiciones y principios generales de la misma (asunto C-310/14, apdo. 36); este precepto tiene, por tanto, un ámbito de aplicación más amplio que el art. 4.2.m), que se ocupa solo de las acciones revocatorias concursales.

El problema de la amplitud de esta prueba es que puede comprender hechos negativos y provocar una inversión de la carga. Esta cuestión corresponde, en principio, al Derecho procesal nacional dado que no está incluida en el Reglamento. Ahora bien, el principio de efectividad de sus normas «se opone, por un lado, a la aplicación de normas procesales nacionales que harían imposible en la práctica o excesivamente difícil el recurso al art. 13 del Reglamento núm. 1346/2000, al establecer normas demasiado estrictas, en particular, en lo relativo a la prueba negativa de la inexistencia de circunstancias determinadas. Por otro lado, este principio se opone a las normas nacionales relativas a la prueba demasiado poco exigentes, cuya aplicación llevaría, en la práctica, a invertir la carga de la prueba prevista en el art. 13 del mencionado Reglamento» (asunto C-310/14, apdo. 29): no cabe exigir una prueba imposible, pero tampoco invertir sin más. En este contexto, el papel del demandante es probar que el acto es impugnable de acuerdo con la lex fori concursus y solo intervenir en caso de que el tribunal entienda que el demandado «ha demostrado efectivamente, a la luz de las reglas habitualmente aplicables según su Derecho procesal nacional», que el acto es inatacable (asunto C-310/14, apdo. 44). De todos modos, el equilibrio es delicado y no parece que vaya a eximir a la administración concursal de una valoración ex ante de las probabilidades de éxito, aunque las consecuencias económicas se ven enjugadas por la vis attractiva.

4. La jurisprudencia del Tribunal de Justicia se ajusta a la lógica del art. 13.16 del Reglamento 1215/2012, y es encomiable en la medida en que hace más difícil que se 
impida la operatividad de la lex fori concursus. Lo que no obsta a que sea mucho más complicada la impugnación de un acto transfronterizo que la de uno doméstico con el consiguiente menoscabo para los intereses del concurso. De ahí que la supresión de este precepto siga siendo la solución a promover o, en su defecto, la opción por aplicar solo la lex causae si se entendiera imprescindible la defensa de las legítimas expectativas de terceros. Aunque estas bien podrían encontrar acomodo en una armonización puntual.

Laura CARBALlo PiÑEIRo

Universidad de Santiago de Compostela

http://dx.doi.org/10.17103/redi.68.1.2016.3b.02

\subsection{Competencia judicial internacional. Reglamento 44/2001}

2016-3-Pr

COMPETENCIA JUDICIAL INTERNACIONAL.-Reglamento 44/2001.-Acción civil en procedimiento penal.-Acción civil ante los tribunales de otro Estado miembro.-Litispendencia internacional.-Identidad de objeto, partes y causa.-Momento de presentación de la demanda.

Preceptos aplicados: arts. 1, 27 y 30 del Reglamento (CE) núm. 44/2001.

Sentencia del TJUE (Sala 3..$^{a}$ ), de 22 de octubre de 2015, asunto C-523/14, Aannemingsbedrijf Aertssen NV, Aertssen Terrassements SA/VSM Machineverhuur BV, Van Someren Bestrating BV, Jos van Someren. Ponente: Sra. C. Toader.

\section{F.: curia.europa.eu.}

1) El artículo 1 del Reglamento (CE) $n^{\circ} 44 / 2001$ del Consejo, de 22 de diciembre de 2000, relativo a la competencia judicial, el reconocimiento y la ejecución de resoluciones judiciales en materia civil y mercantil, debe interpretarse en el sentido de que una denuncia con personación como actor civil presentada ante un juez de instrucción está incluida en el ámbito de aplicación de ese Reglamento en la medida en que tiene por objeto la indemnización pecuniaria del perjuicio alegado por el denunciante.

2) El artículo 27, apartado 1, del Reglamento $n^{\circ} 44 / 2001$ debe interpretarse en el sentido de que una demanda ha sido formulada, a los efectos de esta disposición, cuando se ha presentado una denuncia con personación como actor civil ante un juez de instrucción, aunque no se haya completado todavía la fase de instrucción del asunto controvertido.

3) El artículo 30 del Reglamento $n^{\circ} 44 / 2001$ debe interpretarse en el sentido de que, cuando una persona formula una denuncia con personación como actor civil ante un juez de instrucción mediante presentación de un escrito que, según el Derecho nacional aplicable, no debe notificarse antes de dicha presentación, la fecha en la que procede considerar que ese órgano judicial conoce del litigio es la fecha en la que se formuló la denuncia.

Nota. 1. Uno de los primeros comentarios de urgencia que se pueden encontrar en Internet sobre la sentencia que anotamos señala que no se trata de una mera corner piece, sino de un elemento principal del Reglamento 44/2001. Así es. Como en buena 
parte de los casos en los que las normas europeas se imbrican de forma necesaria con el Derecho procesal de los Estados miembros los problemas de interpretación y aplicación son potencialmente importantes, pues no se trata del Derecho procesal, sino de los múltiples y diferentes Derechos procesales. Y la necesidad de ofrecer una respuesta autónoma y uniforme plantea un reto de mayor envergadura. En el caso presente existe un elemento accesorio de complejidad, puesto que al heterogéneo Derecho procesal civil se le une la vertiente penal de la responsabilidad civil. El marco general del problema presenta procedimientos penales y no penales sobre, adelantémoslo, materia civil. Un puzzle en el que el demandante se «ve obligado» a plantear una demanda que no quiere plantear y a solicitar al órgano judicial ante el que la presenta que se abstenga de conocer. Curioso, pero entendible a la luz de unos hechos que adquieren singular importancia y que paso a describir de forma muy sintética (2) para valorar, a continuación, la respuesta que el TJ da a las cuestiones planteadas ( 3 a 5) y añadir alguna reflexión sobre el Derecho español (6).

2. Las demandantes plantearon un procedimiento penal (denuncia con personación como actor civil) contra una pluralidad de demandados ante un tribunal belga. En esta denuncia ya se incluía una evaluación provisional del perjuicio patrimonial sufrido por las acciones presuntamente delictivas de los demandados de 200.000 euros; simplificando, se ejercitaba la acción civil. A continuación, solicitaron ante un tribunal holandés un embargo preventivo contra los demandados en el procedimiento belga (o contra algunos de ellos) que se concedió en primera instancia, pero que fue levantado posteriormente ante la alegación de los demandados de que la demanda planteada en Bélgica no podría equivaler a la demanda que el Derecho procesal holandés vincula al otorgamiento de la medida provisional. La nueva solicitud de embargo, ante el mismo tribunal, fue estimada a condición de que se presentase una (la) demanda principal en el plazo de un mes. Ante este hecho, las demandantes presentaron una (la) demanda principal ante otro tribunal holandés, al tiempo que, con base en el art. 27 del Reglamento 44/2001, le pedían que se declarase incompetente puesto que un tribunal belga estaba conociendo con anterioridad del mismo asunto. Los demandados, por su parte, alegan que la denuncia con personación como actor civil planteada en Bélgica está excluida del ámbito de aplicación del citado Reglamento y que no existía la identidad exigida por su art. 27.

3. La posición del tribunal holandés es ortodoxa en cuanto a la calificación de las pretensiones y acorde con el tradicional entendimiento del Reglamento: la acción en uno y otro caso es de naturaleza civil y las partes son las mismas. Sin embargo, las dudas se suscitan en torno a si, a la luz del procedimiento penal y la fase de instrucción en la que se encuentra (inconclusa), la demanda estaría efectivamente comprendida dentro del ámbito de aplicación material del Reglamento; si es así, si puede considerarse que existe una "demanda formulada», y en caso positivo, cuándo ha de considerarse formulada (cuestiones prejudiciales primera a tercera). Para el caso de que la respuesta fuese negativa, se plantean otras varias cuestiones que el TJ obvia en función de las respuestas que da a las tres primeras y que nosotros igualmente obviamos.

4. La respuesta a la primera cuestión prejudicial es simple y previsible. Existen ya numerosos precedentes (casos Sonntag o Krombach, entre otros) y datos (arts. 1, 5.4 del Reglamento) que la avalan: inclusión de la denuncia con personación como acción civil a los efectos de obtener una indemnización pecuniaria por el perjuicio alegado. Otro tanto ocurre con la respuesta a la segunda cuestión, que el TJ reconduce a saber si concurre la triple identidad exigida por el art. 27 del Reglamento. La 
tradicional jurisprudencia del citado TJ conduce claramente a afirmar la identidad de objeto, causa y partes.

5. La tercera cuestión (cuándo se considera presentada la demanda) puede ser más trascendente en función de cómo se configure el ejercicio de la acción civil en el proceso penal. De hecho el problema que subyace a la segunda cuestión prejudicial está vinculado más con el momento (dentro de la instrucción penal) que con la idea de triple identidad. Los precedentes aludidos sobre la responsabilidad civil derivada del ilícito penal eran claros y el tema se resuelve de forma simple. Sin embargo, la solución uniforme del art. 30 del Reglamento parece descansar más sobre los distintos modelos procesales de los Estados miembros previstos para los procedimientos civiles (véase punto 57 de la sentencia), que para las situaciones de acciones civiles en procedimientos penales. El TJ la interpreta de forma natural a la luz de las circunstancias del caso que, recordemos, parte de una denuncia con personación como actor civil en la que ya se detallaban los hechos, los demandados y la reclamación pecuniaria que se reclamaba. Como según el Derecho nacional aplicable (belga) no era preciso notificar el escrito a los demandados antes de la presentación, la fecha clave es la de formulación de la denuncia.

6. Nada que objetar, salvo que la cuestión puede que no esté tan clara en otros supuestos o, si lo está, puede que no responda totalmente a la finalidad de la regla. La razón de la litispendencia se cifra por el TJ en reducir al máximo la posibilidad de procedimientos paralelos y evitar que se dicten resoluciones inconciliables. Para esta última bastaría con que uno de los procedimientos no continúe o con esperar a que el primero que concluya sirva para frenar el inconcluso. Pero el elemento cronológico es algo más que una forma de decidir. Que sea el primer tribunal llamado el que tenga la prioridad es un elemento que combate los comportamientos oportunistas del demandado. En el caso, el demandante tuvo la posibilidad de elegir el momento y el tribunal y así se lo reconoce el TJ. Sin embargo, en otras ocasiones la acción civil se planteará de forma más compleja.

En el sistema procesal español puede ser ejercitada en el proceso penal por el Ministerio Fiscal o por el perjudicado; y, cuando correspondiere, será ejercitada en todo caso por el primero si el segundo no la reserva para su ejercicio en el correspondiente procedimiento civil. Esta legitimación ya nos plantea una cuestión de valorar, por ejemplo, si existe identidad de partes cuando en el proceso penal español la acción civil la ejerce el Ministerio Fiscal y en el proceso incoado en otro Estado miembro el concreto perjudicado (o el causante del daño contra el perjudicado persiguiendo una declaración de no responsabilidad). Identidad que, a mi juicio, debería negarse. Pero también abre la puerta a otro tipo de supuestos.

Cuando es el Ministerio Fiscal el que procede a su ejercicio, este tiene lugar tras la conclusión de la instrucción, en el momento de la calificación (aunque también se ha defendido que dicho momento sería cuando dicha calificación se eleva a definitiva en el acto del juicio penal). En todo caso, se trata de momentos en los que una instrucción está en curso. Cuando el procedimiento comienza por querella o denuncia de ofendido o perjudicado (cierta analogía con el caso conocido por el TJ), tampoco puede entenderse que es ese el momento de "presentación de la demanda" a efectos de litispendencia. Se trata de un acto de activación potencial de una instrucción. Sí cabría pensar en el momento de su posterior admisión a trámite, que ha sido considerado como momento crítico en materia de prejudicialidad penal en el proceso civil. Pero tampoco es esta una conclusión que se acomode a las exigencias de la litispendencia que analizamos a la luz del contenido típico de la querella (arts. 277 y ss. LECrim) y menos aún de la denuncia (arts. 251 y ss. LECrim). 
El denominador común de las situaciones anteriores es que los momentos de ejercicio de la acción civil no son necesariamente el primer momento procesal en el que la controversia (contemplada esta en términos generales) aflora. El causante del daño, alertado por la apertura del procedimiento penal, puede plantearse buscar un distinto tribunal competente para discutir la responsabilidad civil, y ello podría paralizar su ejercicio en el procedimiento penal. Si el dañado tiene interés en que conozca el juez penal de la posible responsabilidad civil (o un juez civil, mediante la reserva de acción civil) tiene que tener en cuenta este dato y no acogerse a la tradicional comodidad que el procedimiento penal ofrece en cuanto a la proposición y práctica de prueba y los costes procesales. Tiene que estar alerta y, para curarse en salud, valorar si le conviene ya interponer la acción civil ante el tribunal competente.

Santiago Álvarez GonZÁLEz

Universidad de Santiago de Compostela

http://dx.doi.org/10.17103/redi.68.1.2016.3b.03

\subsection{Competencia judicial internacional: Reglamento 2201/2003}

2016-4-Pr

COMPETENCIA JUDICIAL INTERNACIONAL.-Reglamento Bruselas II bis.Responsabilidad parental._Ámbito de aplicación material.-Sumisión expresa.-Comparecencia mediante mandatario ad litem.

Preceptos aplicados: arts. 1.1.b) y 12.3.b) Reglamento Bruselas II bis.

Sentencia TJUE (Sala 4. ${ }^{a}$ ), de 15 de octubre de 2015, asunto C-215/15, Vasilka Ivanova Gogova y Ilia Dimitrov Iliev. Ponente: Sra. K. Jürimäe.

\section{F.: curia.europa.eu.}

[...] 1) Está incluida en el ámbito de aplicación material del Reglamento núm. 2201/2003, del Consejo, de 27 de noviembre de 2003, relativo a la competencia, el reconocimiento y la ejecución de resoluciones judiciales en materia matrimonial y de responsabilidad parental, por el que se deroga el Reglamento (CE) núm. 1347/2000, la acción por la que uno de los progenitores solicita al juez que supla la falta de consentimiento del otro progenitor al viaje de su hijo menor de edad fuera del Estado miembro en que este reside y a la expedición de un pasaporte a su nombre, incluso en el caso de que la resolución judicial que se dicte al término de dicha acción deba ser tenida en cuenta por las autoridades del Estado miembro del que el menor es nacional en el procedimiento administrativo de expedición de ese pasaporte.

2) El artículo 12, apartado 3, letra b), del Reglamento núm. 2201/2003 debe interpretarse en el sentido de que la competencia de los tribunales para conocer de una demanda en materia de responsabilidad parental presentada ante ellos no puede considerarse "aceptada expresamente o de cualquier otra forma inequívoca por todas las partes en el procedimiento", en el sentido de dicha disposición, por el simple motivo de que el mandatario ad litem que representa al demandado, designado de oficio por esos tribunales ante la imposibilidad de notificar a este último el escrito de demanda, no haya alegado la falta de competencia de los citados tribunales.

Nota. 1. Una mujer búlgara solicita a un juzgado del Estado de su nacionalidad autorización para expedir un pasaporte a su hija (búlgara), debido a que el padre, 
también búlgaro, no la concede. Como consecuencia, el juzgado plantea tres cuestiones prejudiciales al TJUE. La primera versa sobre el ámbito material del Reglamento (CE) núm. 2201/2003 del Consejo, de 27 de noviembre, relativo a la competencia, el reconocimiento y la ejecución de resoluciones judiciales en materia matrimonial y de responsabilidad parental, por el que se deroga el Reglamento (CE) núm. 1347/2000 (DO L 228, de 23 de diciembre de 2003, en adelante Reglamento Bruselas II bis o RBII bis), esto es, sobre la aplicación de este instrumento a la determinación de la competencia judicial internacional en el supuesto (infra 2); las otras dos cuestiones se reconducen a una, relativa a la interpretación del foro de la sumisión expresa dispuesto en el art. 12.3.b) RBII bis (infra 3). Interesa indicar que la menor reside en Milán con su madre, que ejerce la custodia de forma efectiva desde que se rompiera la convivencia con el padre; y que las relaciones entre este, también residente en Italia, y la niña se limitan a visitas cada dos o tres semanas. Ello no obstante, el Código de Familia de Bulgaria exige acuerdo entre ambos progenitores para la expedición del pasaporte, y prevé la necesidad de acudir la autoridad judicial (búlgara) del domicilio de la menor para que decida si tal acuerdo no concurre.

2. La primera cuestión prejudicial obliga al TJUE a determinar si la solicitud dirigida a la autoridad búlgara para que autorice la renovación del pasaporte y un viaje al extranjero es «materia civil», y si forma parte de las «medidas de responsabilidad parental» a que refiere el art. 1.1.b) RBII bis. Y el Tribunal responde de forma afirmativa, en la línea de sus resoluciones previas, en las que siempre ha adoptado una interpretación amplia [véase STJUE (Gran Sala) de 27 de noviembre de 2007, asunto C-435/06, $C$., y Nota de Rodríguez Pineau, E., en REDI 2007-19-Pr; STJUE (Sala 3. ${ }^{\text {) }}$ de 2 de abril de 2009, asunto C-523/07, A.; STJUE (Sala 2. ${ }^{\text {a) }}$ de 26 de abril de 2012, asunto C-92/12, Health Service Executive y $S$. C., A. C. y Notas de Álvarez González, S., en REDI-2012-22-Pr y Durán Ayago, A., en AEDIPr, t. 12, 2012, pp. 953-960].

Ciertamente, en atención a la necesaria interpretación autónoma del concepto «materia civil», el TJUE insiste en que este puede abarcar también cuestiones de Derecho público. No obstante, en lugar de aportar criterios que ayuden en esta calificación (¿qué son, entonces, «materias civiles» a efectos de la aplicación del RBII bis?), reconduce el concepto a «todas las demandas, medidas o resoluciones en materia de responsabilidad parental» (véase § 26). Así, parece que a juicio del TJUE lo importante es, únicamente, determinar si la medida lo es sobre «responsabilidad parental». Al respecto, recuerda que no cabe entender la enumeración del art. 1.2 RBII bis como exhaustiva (véase § 27) y que es preciso atender al objeto de la demanda (véase § 28). De esta forma, en el caso en concreto, a la luz de dicho objeto, esto es, analizando en qué consiste la medida controvertida, afirma que pertenece a la responsabilidad parental «tal y como se define en el art. 2.7 RBII bis» (véase $§ 29$ de la sentencia). No explicita, empero, las razones que fundamentan esta aseveración, como tampoco explica por qué ignora la argumentación del AG (véanse Conclusiones del Abogado General Sr. Paolo Mengozzi, presentadas el 10 de septiembre de 2015), partidario de incluir la medida en la definición del derecho de visita contenida en el art. 2.10 RBII bis, que abarca las medidas referidas al derecho de trasladar a un menor a un lugar distinto al de su residencia habitual durante un periodo de tiempo limitado.

3. En la medida en que resulta de aplicación la normativa institucional, se ha de partir de que el art. 8 RBII bis dispone la competencia general de las autoridades del EM donde tenga su residencia habitual el/la menor. La autorización, por consiguiente, debería solicitarse, en principio, en Italia. Pero el art. 12.3 RBII bis contempla un foro alternativo, basado en la prorrogatio fori, para demandas centradas exclusivamente en 
la responsabilidad parental, esto es, no vinculadas a otra sobre el vínculo matrimonial. En virtud de este precepto, las partes podrían someter la controversia a las autoridades de otro EM (en este caso, de Bulgaria), si la menor está estrechamente vinculada a esas autoridades y siempre que la competencia sea aceptada «expresamente o de cualquier forma inequívoca por todas las partes en el procedimiento en el momento de presentar el asunto ante el órgano jurisdiccional y la competencia responda al interés superior del menor». La primera condición concurre en el supuesto, ya que la menor es nacional del EM ante el que se presenta la demanda; pero la segunda no, toda vez que, a juicio del Tribunal, no cabe deducir aceptación de la competencia por parte del padre, que no compareció en el procedimiento. En efecto, esta incomparecencia obligó a la autoridad búlgara a nombrar un mandatario ad litem, que no impugnó la competencia judicial internacional (véase § 41); pero, tal y como ya había afirmado el TJUE en el marco de la interpretación del Reglamento Bruselas I (Reglamento núm. 44/2001 del Consejo, de 22 de diciembre de 2000, relativo a la competencia judicial, el reconocimiento y la ejecución de resoluciones en materia civil y mercantil, $D O$ L 12, de 16 de enero de 2001), no cabe entender que el representante pueda someterse a una autoridad sin que el representado esté al corriente. La sumisión del mandatario, pues, no es sumisión de la parte a la que representa: véase la STJUE (Sala 5. ${ }^{a}$ ) de 11 de septiembre de 2014, asunto C-112/13, A c. B y otros (véase, sobre esta decisión, la Nota de Oró Martínez, C., en REDI-2015-7-Pr y el trabajo de Sánchez Barrilao, J. F. y SÁNCHEz LORENZO, S., "Sumisión tácita, derechos de defensa y competencia judicial internacional en las redes de la cuestión de inconstitucionalidad y de la cuestión prejudicial», La Ley-Unión Europea, núm. 20, noviembre 2014, pp. 5-15).

De esta forma, por una parte, el Tribunal descarta, una vez más, que quepa determinar los efectos jurídicos de los actos procesales del representante en aplicación de la ley del EM ante el que presenta el litigio: la eficacia de los actos del representante, a efectos de determinar si existe sumisión, debe determinarse con arreglo al Reglamento. Y, por otra parte, además refuerza la interpretación restrictiva que precisa el foro del art. 12.3.b) RBII bis, al tratarse de un foro que exceptúa el criterio de proximidad basado en la autonomía de la voluntad, por lo que no caben presunciones en lo que respecta a su concurrencia.

Como no hay sumisión, el TJUE no entra en una última cuestión, cual es si, tal y como el Reglamento exige (véase supra), la competencia responde(ría) al interés de la menor. Pero cabe finalizar avanzando una posible respuesta. Al efecto, se ha de partir de que el art. 12.4 RBII bis dispone una presunción sobre cuándo se entiende que la competencia basada en la prorrogatio fori es en beneficio del/la menor, que es cuando tiene su residencia habitual en el territorio de un tercer Estado que además no sea parte del Convenio de La Haya de 1996. Pero, como quiera que esta presunción no concurre en el supuesto, resulta preciso analizar in casu tal interés, teniendo presente que debe funcionar como «dique de contención» (cfr. Oró MarTínez, C., loc. cit., p. 253) esto es, para que la autoridad a la que se someten las partes decline su competencia si considera que asumirla resultaría perjudicial para el/la menor. A este respecto, no creo conveniente deducir del hecho de que el/la menor tenga su residencia en otro EM que la aceptación de la competencia por las autoridades de otro EM sea contraria al interés del/la menor [véase, sin embargo, en este sentido, Rauscher, T., "Parental Responsibility Cases under the new Council Regulation "Brussels IIA" ", The European Legal Forum, I-2005, pp. 37-45, p. 41, y FD 5 SAP de Barcelona (Sección 12. a) núm. 425/2011, de 21 de julio, JUR 2011/308012], pues tal deducción convertiría en exclusiva la competencia del art. 8 RBII bis, cuando ha sido voluntad del propio legislador articular otro foro basado en la autonomía de la voluntad (de interpretación, 
eso sí, restrictiva). Es preciso atender a otros datos que podrían permitir afirmar la concurrencia de interés, como, por ejemplo, el hecho de que el asunto litigioso guarde cierta relación con el ejercicio del poder público, como ocurría en este caso.

Patricia OREJUdo PRIETo de los Mozos

Universidad Complutense de Madrid

http://dx.doi.org/10.17103/redi.68.1.2016.3b.04

\subsection{Competencia judicial internacional: Reglamento 4/2009}

2016-5-Pr

COMPETENCIA JUDICIAL INTERNACIONAL.-Crisis matrimonial, Responsabilidad parental y obligación de alimentos respecto de menores de edad.-Accesoriedad de la demanda de alimentos a la acción de responsabilidad parental.

Preceptos aplicados: art. 3, letras c) y d) del Reglamento (CE) núm. 4/2009.

Sentencia del TJUE (Sala 3. ${ }^{a}$ ), de 16 de julio de 2015, asunto C-184/14, A y B. Ponente: Sra. C. Toader.

\section{F.: curia.europa.eu.}

27. [...] habida cuenta de la conjunción "o» que figura en el artículo 3, letras c) y d), del Reglamento [...], los criterios de atribución de competencia establecidos en dichos preceptos se excluyen mutuamente o si esta conjunción significa que los jueces competentes para conocer de la acción de separación judicial y de la acción relativa a la responsabilidad parental respectivamente pueden, tanto el uno como el otro, conocer válidamente de una demanda relativa a la obligación de alimentos a favor de los hijos menores de edad.

28. [...] tal cuestión se plantea únicamente si se considera que la demanda relativa a una obligación de alimentos a favor de un hijo menor de edad es accesoria tanto a una "acción relativa al estado de las personas» como a una "acción relativa a la responsabilidad parental» en el sentido de estas disposiciones, y no únicamente a una de estas acciones.

29. [...] procede determinar el alcance del concepto "demanda accesoria» que figura en el artículo 3, letras c) yd), del Reglamento.

32. Esta interpretación debe buscarse teniendo en cuenta el tenor de la disposición de que se trata, así como su contexto y el objetivo perseguido por la normativa en cuestión.

48. [...] el artículo 3, letras c) y d), del Reglamento [...] debe interpretarse en el sentido de que, cuando un órgano jurisdiccional de un Estado miembro conoce de una acción de separación o de ruptura del vínculo conyugal entre los padres de un hijo menor de edad y un órgano jurisdiccional de otro Estado miembro conoce de una acción de responsabilidad parental en relación con ese menor, una demanda relativa a una obligación de alimentos a favor de ese hijo solo es accesoria a la acción relativa a la responsabilidad parental en el sentido del artículo 3, letra d), de dicho Reglamento.

Nota. 1. La sentencia que se analiza se refiere a una demanda relativa a una obligación de alimentos a favor de hijos menores de edad, concomitante a un procedi- 
miento de crisis matrimonial — separación de los padres, ambos nacionales italianos-, presentada en un Estado miembro distinto de aquel en el que los hijos tienen su residencia habitual (Londres). En el asunto de referencia se encuentran pendientes entre las partes dos demandas distintas en dos Estados miembros diferentes: por un lado, una acción sobre estado de las personas - la relativa a la separación judicialincoada en Italia en virtud del art. 3.1.b) RBII bis y, por otro lado, otra acción referente a la responsabilidad parental respecto de los hijos en común, presentada en Londres al amparo del art. 8.1 RBII bis. En este contexto se plantea el carácter accesorio de las eventuales demandas de alimentos respecto las anteriores acciones, a los efectos de determinar, entre las jurisdicciones en presencia: los tribunales ingleses y los italianos, los competentes para conocer y resolver sobre estas en virtud del art. 3, letras $c$ ) y d) del Reglamento (CE) núm. 4/2009. Dentro del ámbito de aplicación de este instrumento europeo, la cuestión controvertida en cuanto a su aplicación se circunscribe únicamente a las acciones de alimentos ejercitadas frente al progenitor no custodio respecto de los hijos, no así respecto de las eventuales demandas de alimentos entre los ex cónyuges — quedando fuera de las cuestiones prejudiciales remitidas-. Desde esta perspectiva se plantea al Tribunal de Justicia cuál es el concreto alcance del concepto «demanda accesoria» que recoge el art. 3 en sus letras c) y d) del Reglamento, para que determine si en un caso como este en el que hay dos procedimientos pendientes en dos países miembros distintos — sobre estado de las personas y responsabilidad parental, respectivamente- es posible determinar la accesoriedad de la acción de alimentos a ambas acciones indistintamente $\mathrm{y}$, por tanto, otorgar competencia a las dos jurisdicciones implicadas por igual para conocer y resolver, dejando a elección del demandante tal opción; o si por el contrario, únicamente puede determinarse la accesoriedad de la demanda de alimentos respecto de una de ellas, resultando supuestos excluyentes entre sí, y en este último caso cuál sería la acción de la que resultaría accesoria.

2. En principio, el tenor literal de este precepto en un caso como el que se analiza parece que permitiría al operador jurídico considerar que una eventual demanda relativa a una obligación de alimentos a favor de un hijo menor de edad puede entenderse accesoria tanto a la acción sobre la ruptura del vínculo matrimonial — procedimiento incoado ante la jurisdicción italiana - como a la acción sobre la responsabilidad parental - pendiente ante los tribunales ingleses-. De tal manera que, al considerarse que la demanda relativa a una obligación de alimentos a favor de los menores fuera accesoria tanto a la acción sobre la responsabilidad parental, en el sentido del art. 3, letra d), del Reglamento, como a la acción sobre el estado de las personas, en el sentido del art. 3, letra $c$ ), de dicho Reglamento, cabría presentar la acción de alimentos ante cualquiera de estas jurisdicciones a elección del demandante. No obstante, en su labor interpretativa el TJUE no se puede ceñir exclusivamente al tenor literal del precepto a aplicar — que en este caso tampoco es inequívoco-, sino que existen otros referentes hermenéuticos que debe seguir según su propia jurisprudencia, como son el objeto y el contexto de la norma (véase entre otras, STJUE de 2 de abril de 2009, C-523/07, § 34); criterios estos que se deducen expresa e implícitamente del propio Reglamento.

3. En lo que respecta al ámbito de decisión del tribunal del foro para determinar el alcance del concepto "demanda accesoria» para declarar su competencia en la materia, el Tribunal de Justicia se muestra rotundo: no cabe calificación ex lege fori (§ 30). Una cosa es que los tribunales nacionales tengan reconocida su eventual competencia judicial internacional para conocer de la acción sobre crisis matrimonial o sobre responsabilidad parental — fundamentando su competencia en el RBII bis 
aunque no se mencione expresamente, descartándose así la remisión a las reglas de competencia del Derecho nacional (véase RodríGuez VÁzouez, M. ${ }^{a}$ A., «La regulación del Reglamento 4/2009 en materia de obligaciones de alimentos: competencia judicial internacional, ley aplicable y reconocimiento y ejecución de sentencias», REEI, 2010, núm. 19, p. 13)—, respecto de la cual pueda declararse la accesoriedad de una eventual demanda sobre alimentos en virtud de las letras c) y d) del art. 3 del Reglamento, respectivamente, y otra cosa muy distinta es entender que contiene una remisión expresa al Derecho de los Estados miembros para determinar el sentido y el alcance de esta disposición. La referencia expresa a la ley del foro recogida en este precepto no significa que el alcance del concepto «demanda accesoria» pueda dejarse a la apreciación de los órganos jurisdiccionales de cada Estado miembro en función de su Derecho nacional, sino que se exige una interpretación autónoma y uniforme que debe realizarse en función del contexto y el objetivo perseguido por el instrumento en cuestión, en aras de garantizar una aplicación uniforme del Derecho de la Unión (véase entre otras, STJUE de 30 abril de 2014, C-26/13, Kásler y Káslerné Rábai, $\S 37)$. Por lo que a los objetivos perseguidos se refiere, la labor hermenéutica de esta norma exige la atribución de un significado autónomo e inequívoco de los términos que aparecen en ella, entre otras razones para garantizar la no discriminación entre situaciones similares, así como el respeto de los mismos derechos y obligaciones para las partes con independencia del foro, facilitando de esta manera por tanto el cobro de los alimentos, que es uno de los objetivos de este instrumento (véase EsPINOsA CALABUiG, R., "Las obligaciones alimenticias hacia el menor y su relación con la responsabilidad parental: los Reglamentos 4/2009 y 2201/2003», en BARUFFI, C. y CAFARI Panico, R., Le nuove competenze comunitarie. Obbligazioni alimentari e successioni, Cedam, 2009, p. 71), junto con la buena administración de justicia (considerando 15), de la cual se deduce que el tribunal mejor posicionado para conocer en este caso sería el de residencia habitual de los menores (acreedores de alimentos). En lo que respecta al contexto, de este deviene la necesidad de tomar en consideración el interés superior del menor en la interpretación del art. 3, lo que se deduce del propio instrumento por varios motivos. En primer lugar, y en general para todo el Reglamento, por referencia expresa al Convenio de La Haya de 2007 (considerando 8) en el que este criterio tiene consideración primordial en todas las medidas concernientes a los niños (véase Duncan, W., "The New Hague Convention of 23 November 2007 in the International Recovery of Child Support and Other Forms of Family Maintenance», en Yearbook of Private International Law, vol. X, 2008, pp. 313-332). En segundo lugar, en concreto para este precepto, por la distinción de supuestos de hecho que el art. 3 realiza tomada directamente de las disposiciones del RBII bis (siguiendo el objetivo marcado en su considerando 5), en el que en materia de responsabilidad parental las reglas de competencia han sido concebidas en función del interés superior del menor - y la recta administración de justicia- (considerando 12).

4. La necesidad de tomar en consideración el interés superior del menor, así como los objetivos perseguidos por el art. 3 del Reglamento y del contexto en el que este se inscribe, determina que solo puede considerarse accesoria a la acción en materia de responsabilidad parental. En consecuencia, el Tribunal de Justicia sentencia que cuando un órgano jurisdiccional de un Estado miembro conoce de una acción de separación o de ruptura del vínculo conyugal entre los padres de un hijo menor de edad y un órgano jurisdiccional de otro Estado miembro conoce de una acción de responsabilidad parental en relación con ese menor, una demanda relativa a una obligación de alimentos a favor de ese hijo solo es accesoria a la acción relativa a la responsabilidad parental en el sentido del art. 3, letra d), del Reglamento. De esta 
manera, el Tribunal de Justicia determina la accesoriedad de la demanda de alimentos en función del acreedor de dicha obligación y la especial protección que ha de profesarse a los menores, mediante la incorporación del criterio interés superior del menor como valor como referente hermenéutico en su jurisprudencia (fundamentando esta aproximación en la obligación derivada del art. 24, apdo. 2 de la CDFUE).

Clara Isabel CORDERO ÁLVAREZ Universidad Complutense de Madrid http://dx.doi.org/10.17103/redi.68.1.2016.3b.05

\subsection{Reconocimiento y ejecución de resoluciones: Reglamento 2201/2003}

2016-6-Pr

\section{EJECUCIÓN EN UN ESTADO MIEMBRO DE UNA MULTA COERCITIVA PARA GARANTIZAR EL DERECHO DE VISITA.-Competencia judicial y ejecución de resoluciones judiciales en materia civil y mercantil.-Materias excluidas.-De- recho de familia.-Competencia, reconocimiento y ejecución de resoluciones en materia de responsabilidad parental.-Ejecución de la multa coercitiva.}

Preceptos aplicados: arts. 1, apdo. 2, y 49 del Reglamento (CE) núm. 44/2001; arts. 26, 28, apdo. 1, 41, apdo. 1, 47, apdo. 1, del Reglamento (CE) núm. 2201/2003.

Sentencia del TJUE (Sala 1. ${ }^{a}$ ), de 9 de septiembre de 2015, asunto C-4/14, Christophe Bohez c. Ingrid Wiertz. Ponente: M. Berger.

\section{F.: curia.europa.eu.}

1) El artículo 1 del Reglamento (CE) núm. 44/2001 del Consejo, de 22 de diciembre de 2000, relativo a la competencia judicial, el reconocimiento y la ejecución de resoluciones judiciales en materia civil y mercantil, debe interpretarse en el sentido de que ese Reglamento no se aplica a la ejecución en un Estado miembro de una multa coercitiva impuesta en una resolución, dictada en otro Estado miembro, relativa al derecho de custodia y al derecho de visita para garantizar el respeto de dicho derecho de visita por el titular del derecho de custodia.

2) El cobro de una multa coercitiva impuesta por el juez del Estado miembro de origen que resolvió sobre el fondo en lo relativo al derecho de visita para garantizar la efectividad de ese derecho forma parte del mismo régimen de ejecución que la resolución sobre el derecho de visita que dicha multa coercitiva garantiza y esta debe, por ello, ser declarada ejecutiva conforme a las reglas establecidas por el Reglamento (CE) núm. 2201/2003 del Consejo, de 27 de noviembre de 2003, relativo a la competencia, el reconocimiento y la ejecución de resoluciones judiciales en materia matrimonial y de responsabilidad parental, por el que se deroga el Reglamento (CE) núm. 1347/2000.

3) En el marco del Reglamento núm. 2201/2003, las resoluciones extranjeras que condenen al pago de multas coercitivas solamente pueden ejecutarse en el Estado miembro requerido cuando su cuantía haya sido fijada definitivamente por los tribunales del Estado miembro de origen.

Nota. 1. La sentencia objeto del presente comentario responde a una petición de decisión prejudicial, que afecta a la interpretación de los arts. 1, apdo. 2, y 49 del 
Reglamento 44/2001 (en adelante, RBI) y de los arts. 47, apdo. 1, y 28 del Reglamento 2201/2003 (RBII bis), en el marco de un litigio sobre la ejecución en Finlandia de una multa coercitiva, impuesta por un tribunal belga, para garantizar el respeto del derecho de visita. El Korkein oikeus (Tribunal Supremo) de Finlandia planteó al TJUE cinco cuestiones prejudiciales exhaustivamente analizadas por el TJUE y de las cuales tres de ellas, por constituir el núcleo decisorio, son objeto del presente comentario. Esta nota analiza, en primer lugar, la cuestión prejudicial relativa al instrumento legal aplicable a la ejecución en otro Estado miembro de multas coercitivas que garantizan el derecho de visita; en segundo lugar, la cuestión sobre el procedimiento de ejecución a seguir para hacer valer la multa coercitiva en otro Estado de la UE; y, en tercer lugar, aquella relativa a la fijación de la cuantía definitiva de la multa por el juez de origen como condición imprescindible para la ejecución transfronteriza de la multa coercitiva.

2. La primera cuestión afecta a la determinación de si el art. 1 RBI debe interpretarse en el sentido de que el RBI se aplica a la ejecución en un Estado miembro de una multa coercitiva impuesta para garantizar el respeto del derecho de visita por parte del titular del derecho de custodia. El TJUE recuerda de forma didáctica y bien fundamentada las cuestiones más básicas del ámbito de aplicación material del RBI, que se limita a la «materia civil y mercantil», determinándose esta esencialmente en atención a los rasgos que caracterizan la naturaleza de las relaciones jurídicas entre las partes del litigio o el objeto de este, en definitiva, de la naturaleza del derecho subjetivo cuya violación hizo que se ordenase la ejecución (véase STJUE de 18 de octubre de 2011, Realchemie Nederland BV c. Bayer CropScience AG, asunto C 406/09, apdos. 39 y 42 y jurisprudencia citada, y Nota de DE Miguel Asensio, P., en REDI, vol. LXIV, 2012, pp. 180-184), en nuestro caso, de la condena al pago de una multa coercitiva, impuesta por un órgano jurisdiccional de otro Estado miembro para garantizar el derecho de visita. Consecuente con ello, el TJUE examina la finalidad de la multa coercitiva en cuestión, entendiendo que es la de ejercer presión económica sobre la persona que tiene la custodia para que coopere en la aplicación del derecho de visita, argumentando, en consecuencia, que su naturaleza queda fuera del ámbito de aplicación del RBI [art. 1, apdo. 2, letra a)], siendo de aplicación, sin embargo, el RBII bis, cuyo ámbito material incluye expresamente el derecho de visita [art. 1, apdo. 2, letra $a$ )]. Por esta razón básica, el TJUE declara acertadamente que la multa coercitiva cuya ejecución se solicita en el asunto principal es una medida accesoria que pretende garantizar la salvaguarda de un derecho que no forma parte del ámbito de aplicación del RBI sino del RBII bis, aclarando que este último Reglamento es el aplicable a la ejecución en un Estado miembro de una multa coercitiva fijada en una resolución de otro Estado miembro, en materia de derecho de visita, con el fin de garantizar el respeto a tal derecho.

3. En relación con el procedimiento de ejecución a seguir para el cobro de este tipo de multas coercitivas en otro Estado, para el TJUE lo esencial es determinar si la multa, impuesta por el juez del Estado miembro de origen que resolvió sobre el fondo del derecho de visita forma parte del procedimiento de ejecución del derecho de visita, rigiéndose en consecuencia por el Derecho nacional, como indica el art. 47, apdo. 1, RBII bis o, por el contrario, forma parte del mismo régimen que el derecho de visita que dicha multa garantiza, debiendo, en tal caso, declararse ejecutivo según las reglas establecidas en el RBII bis. Respondiendo a ello, el TJUE recuerda que el principio de «reconocimiento mutuo de las resoluciones relativas al derecho de visita ha sido identificado como una prioridad en el marco del espacio judicial de la UE» y que la especialidad de estas cuestiones obliga a conceder un régimen de ejecución específico, 
menos estricto y automático, recogido en los arts. 28, apdo. 1, y 41, apdo. 1, que se fundamenta en el principio de confianza mutua que impide una revisión del fondo del asunto (art. 26). Esta cuestión planteada es relevante para la práctica internacional atendiendo a criterios de efectividad de estas medidas y habida cuenta del vacío legal existente hasta la fecha por no existir un precepto específico en el RBII bis sobre la ejecución de multas coercitivas que entren en su ámbito de aplicación. El TJUE clarifica adecuadamente la aplicación del RBII bis a la ejecución de este tipo de multas atendiendo a su finalidad y a los objetivos del mencionado Reglamento. Entiende el TJUE que pese a que el RBII bis no incluye una norma sobre la multa coercitiva, como sí hiciera el RBI (y hace el actual RBI bis), «no puede deducirse que la intención del legislador fuera excluir la ejecución de la multa coercitiva del ámbito de aplicación del RBII bis, dado que contribuye al respeto de las resoluciones dictadas en cumplimiento del mismo en materia de derecho de visita, y ello forma parte del objetivo de efectividad que persigue el RBII bis». A la vista de todo lo anterior, el TJUE establece de forma acertada que la multa coercitiva controvertida en el litigio principal tiene carácter accesorio respecto de la obligación principal que garantiza, siendo indudable en consecuencia que la ejecución de estas multas está directamente vinculada tanto a la existencia de la mencionada obligación principal cuanto a su incumplimiento: por tanto, la multa coercitiva impuesta no puede considerarse de forma aislada como una obligación autónoma, sino de manera indisociable al derecho de visita que garantiza y debe regirse por el mismo régimen de ejecución que el derecho de visita, a saber, por los arts. 28, apdo. 1, y 41, apdo. 1, RBII bis.

4. La última de las cuestiones relevantes tratadas en esta sentencia, y también de gran trascendencia práctica, despeja la duda sobre si en virtud del RBII bis las resoluciones extranjeras que condenan al pago de multas coercitivas solo pueden ejecutarse en el Estado requerido cuando la cuantía haya sido fijada definitivamente por los tribunales del Estado de origen. Son bien conocidas las diferencias existentes entre las distintas legislaciones de los Estados miembros; así, como la propia sentencia subraya, entre el Derecho finlandés y el Derecho belga. Consciente de ello, el TJUE recuerda que fue precisamente para evitar las dificultades derivadas de las divergencias legislativas de los Estados miembros sobre multas coercitivas por lo que se añadió el precepto específico sobre tales multas en el Convenio de 27 de septiembre de 1968, cuyo contenido se mantiene en el RBI (y RBI bis), imponiendo que para la ejecución de tales multas la cuantía haya sido fijada definitivamente por los tribunales del Estado de origen. Ante la ausencia de un precepto similar en el RBII bis el TJUE coincide con los argumentos del Abogado General M. Szpunar en el punto 81 de sus conclusiones, afirmando que «la exigencia de solicitar, antes de la ejecución, la liquidación de la multa coercitiva está en sintonía con el carácter sensible que presenta el derecho de visita en el RBII bis». Por esta razón, afirma acertadamente el TJUE, siguiendo dichos argumentos, que, si el titular del derecho de visita reconocido en un Estado miembro solicita la ejecución en otro Estado de una multa coercitiva cuya cuantía definitiva no ha sido fijada por el juez de origen, sería contrario al sistema establecido por el RBII bis, al permitir al juez del Estado de ejecución intervenir en la fijación de la cuantía final. Y ello porque, tal y como argumenta el TJUE, dicha fijación implica un control de los incumplimientos alegados por el titular del derecho de visita, control que es de vital importancia para el interés superior del menor e implica el examen de las razones que dieron lugar a dichos incumplimientos. En consecuencia, como explica el TJUE, únicamente el juez del Estado de origen puede llevar a cabo tales apreciaciones, concluyendo que las resoluciones extranjeras que condenan al pago de multas coercitivas únicamente pueden ejecutarse en el Estado miembro 
requerido cuando su cuantía haya sido fijada definitivamente por los tribunales del Estado miembro de origen. En conclusión, nos encontramos ante una sentencia bien construida que arroja luz sobre tres aspectos de gran trascendencia práctica para la aplicación del régimen de ejecución de las multas coercitivas vinculadas a materias comprendidas en el ámbito del RBII bis, clarificando el procedimiento de ejecución de estas multas, atendiendo al principio de confianza mutua y a los especiales objetivos del RBII bis, y facilitando la eficacia de las decisiones dictadas en materia de derecho de visita y de las medidas coercitivas vinculadas que lo garantizan, siempre que la cuantía haya sido fijada definitivamente por la autoridad competente del Estado de origen.

Lydia Esteve GonZÁLEZ

Universidad de Alicante

http://dx.doi.org/10.17103/redi.68.1.2016.3b.06

2016-7-Pr

RESPONSABILIDAD PARENTAL.-Traslado de menores.-Reconocimiento de sentencia extranjera estableciendo el derecho a decidir la residencia del menor.-Error en la utilización de las normas de competencia por el Tribunal de origen.-Orden público como motivo de denegación del reconocimiento.

Preceptos aplicados: arts. 23.a) y 24 del Reglamento (CE) núm. 2201/2003.

Sentencia del TJUE de 19 de noviembre de 2015, asunto C455/15 PPU, $P$ y $Q$. Ponente: Sra. A. Prechal.

F.: curia.europa.eu.

El artículo 23, letra a), del Reglamento (CE) núm. 2201/2003 del Consejo, de 27 de noviembre de 2003, relativo a la competencia, el reconocimiento y la ejecución de resoluciones judiciales en materia matrimonial y de responsabilidad parental, por el que se deroga el Reglamento (CE) núm. 1347/2000, debe interpretarse en el sentido de que, cuando no exista una violación manifiesta, habida cuenta del interés superior del menor, de una norma jurídica considerada esencial en el ordenamiento jurídico de un Estado miembro o de un derecho reconocido como fundamental en ese ordenamiento jurídico, dicha disposición no permite al órgano jurisdiccional de ese Estado miembro que se considera competente para resolver sobre la custodia de un menor denegar el reconocimiento de la resolución de un órgano jurisdiccional de otro Estado miembro que ha resuelto sobre la custodia de dicho menor.

Nota. 1. Los hechos que dan origen a la sentencia que anotamos son comunes en buena parte de los traslados de menores de un Estado a otro por parte de uno de sus padres (padre o madre), quedando del otro en el país de la anterior residencia. Aún así, merecen describirse para poder entender la cuestión jurídica. Padre y madre son pareja residente en Lituania desde 1997; tuvieron un hijo en 2000; se divorciaron por sentencia de un Tribunal lituano en 2003; se trasladaron a vivir a Suecia en 2005; en 2006, el mismo tribunal lituano que había decretado el divorcio decretó que la residencia del único hijo (entonces de seis años de edad) quedara fijada en el domicilio de la madre, aunque la custodia correspondía a ambos. En 2009 nació un segundo hijo ya en Suecia. Remarca el TJ que ambos niños hablan sueco y están escolarizados en Suecia donde vive la mayor parte de las personas que conocen. 
En 2013 las autoridades suecas dictaron una orden de alejamiento del padre respecto de la madre y los hijos. En 2014 la madre se trasladó a Lituania con sus hijos, los inscribió en el Registro civil y solicitó ante un tribunal lituano medidas provisionales (en el marco de un procedimiento sobre el fondo) sobre la residencia, la custodia del hijo menor y alimentos para ambos. Días después el padre solicitó ante un tribunal sueco la custodia de sus hijos en exclusiva; también pidió ante las autoridades suecas la restitución de los dos hijos de acuerdo con el Convenio de La Haya de 25 de octubre de 1980 sobre los aspectos civiles de la sustracción internacional de menores. Los tribunales lituanos rechazaron el retorno sobre la base del art. 13 del referido Convenio (parece que por considerar que el traslado no habría sido ilícito al no ejercer el padre de forma efectiva la custodia en el momento del traslado). El 18 de febrero de 2015, un Tribunal lituano determinó que la residencia del hijo menor debía fijarse en el domicilio de la madre y condenó al padre a pagar alimentos a los dos hijos. Esta es la resolución cuyo reconocimiento en Suecia - pendiente aún el procedimiento sueco sobre el fondo de la custodia - da origen a la cuestión prejudicial. Previamente el padre había obtenido una resolución provisional en Suecia atribuyéndole la custodia de su hijo menor en exclusiva. El padre se opone al reconocimiento en Suecia de la sentencia lituana por considerarla contraria al orden público sueco. Para dotar de contenido a este orden público, hace hincapié en que el tribunal lituano se habría declarado competente en virtud del art. 15 del Reglamento 2001/2003, incurriendo en un manifiesto error. Ciertamente, la alegación de contrariedad con el orden público es más genérica, aunque el «argumento» principal es este vinculado al control de la competencia del juez de origen.

2. El TJ liquida la cuestión de forma sumaria. Ciertamente la propia elevación de la cuestión prejudicial no deja de llamar la atención: un tribunal sueco se pregunta si la sentencia lituana puede ser contraria al orden público sueco cuando, tan solo se pronuncia - en lo que aquí interesa - sobre el derecho de la madre a determinar la residencia del hijo menor (el padre había desistido de cualquier pretensión sobre el hijo mayor) en un contexto en el que existía una orden de alejamiento del padre respecto de la madre y los hijos (si bien es cierto que — cosas de este tipo de asuntos - había atribuido provisionalmente al mismo padre la custodia del hijo menor). Para apuntalar lo llamativo de la cuestión, se alude a la falta de competencia del juez lituano como un elemento integrante del orden público en función de una interpretación excesivamente literal y extravagante de lo dispuesto en el art. 24 del Reglamento.

3. Respecto del orden público en general, el TJ adopta una perspectiva clásica y consistente con su práctica anterior (apdos. 37 y ss.) en la que tras recordar que no le corresponde establecer el contenido del orden público sueco, pero sí los límites dentro de los cuales este puede operar (véase sobre el alcance y operatividad de este principio Álvarez GonZález, S., "¿Orden público europeo versus orden público internacional de cada Estado?», La gobernanza del interés público global, XXV Jornadas de Profesores de Derecho internacional y relaciones internacionales, Madrid, 2015, pp. 146-181, pp. 163 y ss.) hace una descripción de lo que han de ser esos límites en relación con el art. 23.a) del Reglamento: solo será operativo el orden público cuando el reconocimiento de la sentencia extranjera suponga una «violación manifiesta, habida cuenta del interés superior del menor, de una norma jurídica considerada esencial en el ordenamiento jurídico del Estado requerido o de un derecho reconocido como fundamental en este ordenamiento». Y, continúa el TJ, de los autos no se desprende que exista ni esa norma ni ese derecho fundamental que pudieran ser menoscabadas por el reconocimiento. 
4. En relación con la vinculación entre el orden público y el control de la competencia del juez lituano la respuesta del TJ es igualmente simple, si bien, en este caso, lo llamativo está en la pregunta, que parte de la alegación del padre en virtud de lo dispuesto en el art. 24 del Reglamento. Aquí se señala que no podrá procederse al control de la competencia del juez de origen y que el criterio del orden público no podrá aplicarse a las normas de competencia establecidas en los arts. 3 a 14, pero que no se excluye al art. 15, en el que el Tribunal lituano basó su competencia. El formalista argumento del padre es que el orden público sí podría servir para rechazar el reconocimiento de la sentencia extranjera cuando el juez que la dictó hubiese infringido dicho art. 15 (inclusio unius, exclusio alterius). El estrecho marco de esta nota me impide abundar en la incoherencia del argumento del padre desde el punto de vista de lo que significa realmente el control de la competencia del juez de origen (más allá o al margen de que pudiera o no constituir una razón de orden público), por lo que me permitiré remitirme a otro lugar sobre tal aspecto (ÁLVAREZ GonZÁLEZ, S., "Traslado ilícito de menores, competencia judicial internacional y orden público», La Ley Unión Europea, 2016, pendiente de publicación cuando se redacta esta nota). El TJ tampoco profundiza en el tema. Lo liquida de una forma igualmente formal, señalando que en realidad el art. 15 del Reglamento lo que hace es completar el sistema de los arts. 8 a 14 del mismo, sin entrar en mayores aclaraciones. Lo cierto es que habiendo afirmado, como afirmó, que no existía vulneración de norma o derecho fundamental que pudiera menoscabar el reconocimiento el tema estaba liquidado. Incluso aun considerando que pudieran existir supuestos excepcionales en los que la incompetencia del juez de origen vulnera el orden público del foro (VIRGós SORIANO, M. y GARCIMARTín Alférez, F. J., Derecho procesal civil internacional. Litigación internacional, 2. ${ }^{\text {e ed., Ci- }}$ zur Menor, Thomson Civitas, 2007, pp. 613-614), ello no alivia el test de contradicción o, dicho con otras palabras, la mera incompetencia no es razón bastante.

5. La sentencia resuelve de forma previsible una cuestión prejudicial cuya mayor enjundia, a mi juicio, reside en los motivos que la suscitaron: probablemente la ausencia de un sistema lo suficientemente intuitivo para resolver las relaciones entre los diferentes tipos de procedimientos que se articulan en torno a un traslado internacional (lícito o no) de un menor; probablemente la idea de que el principio de confianza comunitaria (o europea) no puede aceptar una última palabra de los tribunales del Estado al que el menor ha sido desplazado, como idea fuerza que no se deja de repetir para describir de forma simple el paso adelante del Reglamento 2201/2003 respecto del Convenio de La Haya de 1980 - algo real pero que hay que contrastar con los datos de cada caso y, sobre todo, saber qué relevancia tiene en cada momento-; probablemente el hecho de que en todos estos supuestos el «supremo interés del niño» podría acabar por diluir cualquier tipo de andamiaje procedimental más o menos articulado.

\author{
Santiago Álvarez GoNZÁLEZ \\ Universidad de Santiago de Compostela \\ http://dx.doi.org/10.17103/redi.68.1.2016.3b.07
}

\title{
1.6. Ley aplicable: Reglamento Roma II
}

2016-8-Pr

COOPERACIÓN JUDICIAL EN MATERIA CIVIL.-Reglamento (CE) núm. 864/ 2007, del Parlamento Europeo y del Consejo, de 11 de julio, relativo a la ley apli- 
cable a las obligaciones extracontractuales (Roma II).-Art. 4.1 Roma II.-Conceptos de país en el que se produce el daño, daños y consecuencias indirectas del hecho dañoso.-Daños sufridos personalmente por un familiar de una persona fallecida en accidente de tráfico: consecuencias indirectas del hecho dañoso.Ley aplicable.

Preceptos aplicados: art. 4 Roma II.

Sentencia del TJUE de 10 de diciembre de 2015, asunto C-350/14, Florin Lazar v. Allianz SpA. Ponente: M. Safjan.

\section{F.: curia.europa.eu.}

El art. 4.1 Roma II [...], debe interpretarse, a efectos de determinar la ley aplicable a una obligación extracontractual resultante de un accidente de tráfico, en el sentido de que los perjuicios relacionados con el fallecimiento de una persona en dicho accidente ocurrido en el Estado miembro del foro y sufridos por los familiares próximos de esta que residen en otro Estado miembro deben calificarse como "consecuencias indirectas» de ese accidente, en el sentido de dicha disposición.

Nota. 1. Causado por un vehículo no identificado, una ciudadana rumana residente en Italia falleció en un accidente de tráfico ocurrido el 18 de mayo de 2012 en este país. Su padre, el Sr. Lazar, nacional rumano residente en Rumanía, reclama una indemnización de daños patrimoniales y no patrimoniales supuestamente sufridos iure proprio. La compañía aseguradora Allianz S.p.A. fue demandada en el procedimiento (art. 283.1 Codice delle assicurazioni private), como compañía designada por el Fondo di garanzia per le vittime della strada, organismo responsable de la indemnización de los daños causados por la circulación de vehículos no identificados. Intervinieron también la madre y la abuela de la víctima, ambas ciudadanas rumanas residentes en Italia, solicitando la indemnización de los daños patrimoniales y no patrimoniales sufridos iure proprio a raíz del fallecimiento de la víctima. El 10 de julio de 2014, el Tribunale civile de Trieste, órgano jurisdiccional remitente, duda de la interpretación del art. 4.1 Roma II en la parte que establece que «...la ley aplicable a una obligación extracontractual que se derive de un hecho dañoso es la del lugar donde se produce el daño...»: de ello depende el Derecho material aplicable a la existencia y el carácter indemnizable de los daños invocados por el demandante residente en Rumanía, Derecho italiano o Derecho rumano. Desde la óptica del Derecho italiano (arts. 20143 y 2059 CC italiano), el daño resultante del fallecimiento de un familiar es sufrido directamente por el familiar, tomando, en particular, la forma de una lesión a sus derechos de la personalidad, lo que supondría, a diferencia de otros ordenamientos jurídicos europeos donde ese tipo de daño no recibe la misma calificación, dar la razón a un demandante que alega un perjuicio que, sobre la base de ese Derecho nacional, le es propio y que representa la consecuencia material del fallecimiento del miembro de su familia. En vista de ello, el Tribunal de Trieste cuestiona, básicamente, si el art. 4.1 Roma II debe interpretarse, a efectos de determinar la ley aplicable a una obligación extracontractual resultante de un accidente de tráfico, en el sentido de que los perjuicios patrimoniales y no patrimoniales relacionados con el fallecimiento de una persona en un accidente de ese tipo ocurrido en el Estado miembro del foro y sufridos por los familiares próximos de la víctima que tienen su domicilio en otro Estado miembro deben calificarse como «...daño(s)...» o como «...consecuencias indirectas...» de ese accidente, en el sentido de la citada disposición. 
2. Invocando la interpretación autónoma de la que debe ser objeto toda disposición de Derecho de la UE que no contenga una remisión expresa al Derecho autónomo de los Estados miembros, como es el caso del art. 4.1 Roma II, y en orden a garantizar su aplicación uniforme en todos los Estados miembros (apdo. 37 STJUE de 30 de abril de 2014, Kásler y Káslerné Rábai), considera el Tribunal de Justicia (FFDD 21 y 30), siguiendo tanto su tenor literal como el contexto y los objetivos perseguidos por la normativa de la que forma parte (apdo. 35 STJUE de 16 de julio de 2015, Lanigan), que los perjuicios relacionados con el fallecimiento de una persona en un accidente de tráfico ocurrido en el Estado miembro del foro y sufridos por los familiares próximos a la víctima residentes en otro Estado miembro deben calificarse, a efectos de determinar la ley aplicable a una obligación extracontractual resultante de este hecho ex art. 4.1 Roma II, como consecuencias indirectas de ese accidente: por tanto, no son relevantes a la hora de concretar el locus damni como punto de conexión determinante de la ley aplicable del art. 4.1 Roma II.

3. El daño a considerar, a efectos de ley aplicable y en orden a identificar el lugar en el que dicho daño se produce, es el daño directo [FD 23; considerando 16 Reglamento Roma II; Propuesta Reglamento Roma II, COM (2003) 427 final, p. 12]: tras disponer el art. 2 Roma II que «...se entenderá por daños todas las consecuencias resultantes de un hecho dañoso...», el art. 4.1 Roma II opta a efectos de ley aplicable por la ley del país en el que se produce el daño, desechando, a diferencia del art. 7.2 Reglamento 1215/2012 regulador de la competencia judicial internacional en esta materia, el país en el que ocurre el hecho generador del daño, así como el país o países en los que se sufren las consecuencias indirectas de tal hecho. Y este daño directo, en el supuesto de un accidente de circulación, que es el caso que nos ocupa, lo conforman las heridas que provocaron el fallecimiento de la hija del Sr. Lazar, producidas, según consta, en Italia, y no los daños morales o patrimoniales sufridos por los parientes próximos a la víctima, ocurridos en Rumanía, que solo pueden ser calificados como consecuencias indirectas del accidente que fundamenta el litigio principal (FD 25). Se ajusta lo expuesto a lo determinado por el legislador europeo en el considerando 17 Reglamento Roma II cuando estima que, en caso de lesiones personales o daño a la propiedad, el país en el que se produce el daño directo se corresponde con aquel lugar donde se haya sufrido la lesión o se haya dañado la propiedad (en el Informe relativo a la Propuesta Reglamento Roma II, precisamente en relación con los accidentes de circulación, se estima que «...el lugar del daño directo es el de la colisión, independientemente de los posibles perjuicios financieros o morales que se produzcan en otro país...", loc. cit., p. 12).

Identificada la ley aplicable a partir del locus del daño directo, a ella corresponde la tarea de determinar quiénes son las personas que pueden alegar el daño sufrido [art. 15.f) Roma II], esto es, será la ley aplicable determinada a partir de este daño directo la que establezca si los familiares próximos de la víctima pueden alegar los daños sufridos por ellos a raíz del accidente de la víctima. O, lo que es lo mismo, la ley designada determina también las personas que tienen derecho a que se les indemnice el daño que han sufrido personalmente, en concreto, si una persona distinta de la víctima directa puede obtener indemnización del daño moral (por ejemplo: aflicción causada por la muerte de un pariente) o económico (por ejemplo: el causado a los hijos o al cónyuge de un difunto) que se le ha causado «de rebote...», a raíz del daño sufrido por la persona lesionada [Comisión Europea en relación con el art. 11.g) Propuesta de Reglamento Roma II, loc. cit., actual art. 15.f) Roma II].

4. Esta interpretación del art. 4.1 Roma II permite combatir la fragmentación de la ley aplicable, evitando el riesgo de que el daño indemnizable pueda descomponerse 
en una multiplicidad de partes sujetas a una ley diferente en función de los lugares (residencia habitual) en los que las personas distintas de la víctima directa sufran daños (considerando 16 Reglamento Roma II). Además de aportar simplicidad y objetividad a la solución, en tanto que cuanto todos los daños alegados proceden, en realidad, de un mismo origen, favorece también el objetivo de previsibilidad de la ley aplicable: la persona cuya responsabilidad se alega está en condiciones de prever las consecuencias en otros países de su comportamiento o de los comportamientos de las personas de las que debe responder, al igual que la víctima es en principio consciente del marco normativo al que ella o sus bienes quedan expuestos [VON HEIN, J., "Art. 4», en Calliess, G. P. (ed.), Rome Regulations: Commentary on the European Rules of the Conflict of Laws, 2011, p. 402], lo que no sucede de pretender la aplicación de la ley del país donde el sujeto sufre un daño indirecto o donde lo sufren víctimas indirectas, circunstancias que el causante del daño no puede prever de manera razonable. Esta interpretación refuerza, asimismo, la neutralidad de un art. 4 Roma II que no se respetaría si los perjuicios patrimoniales para los causahabientes de una persona fallecida en un accidente de tráfico siempre se localizaran en el lugar de residencia de la víctima correspondiente, así como la idea de proximidad que da base al precepto: si bien no hay duda de que el lugar del accidente presenta vínculos incuestionables con los elementos constitutivos de la responsabilidad, no puede decirse lo mismo respecto del domicilio de la víctima indirecta (apdos. 76 y 77 Conclusiones Abogado General; por analogía, apdo. 21 STJCE de 11 de enero de 1990, Dumez).

Fiel al objetivo de coherencia que debe presidir la aplicación e interpretación de las normativas correspondientes a ley aplicable y a competencia judicial internacional (considerando 7 Reglamento Roma II), lo expuesto se ajusta a las líneas básicas perfiladas por la jurisprudencia del TJUE en relación con el art. 7.2 Reglamento 1215/2012 (anterior art. 5.3 Reglamento 44/CB 1968) regulador de la materia relativa a obligaciones no contractuales en sede de competencia judicial internacional. Así es en lo que respecta a la fundamentación del referido precepto con base solo en los daños directos (apdos. 14 y 15 STJCE de 19 de septiembre de 1995, Marinari; apdo. 20 STJCE de 10 de junio de 2004, Kronhofer; o STJUE de 28 de enero de 2015, Kolasa, que no consideran lugar donde se hubiere producido el hecho dañoso el «...lugar en el que la víctima alega haber sufrido un prejuicio patrimonial debido a un daño inicial sobrevenido y sufrido por ella en otro Estado miembro...»; especialmente, apdos. 13 y 14 STJCE 11 de enero de 1990, Dumez, al entender que los daños alegados por las sociedades matrices eran la consecuencia indirecta de las pérdidas económicas sufridas en un primer momento por sus filiales debido a la revocación de los créditos y posterior paro de las obras; también, Ord. Corte Cass. italiana de 27 de diciembre de 2011, RDIPP, 2012, p. 939; más dudoso, en cambio, Sent. Juzgado de lo Mercantil de Madrid de 5 de julio de 2013, AC 2013/1535, interpretando muy ampliamente el foro no contractual del anterior art. 22.3 LOPJ 1985 en materia de competencia desleal, extendiéndolo a efectos alejados del hecho ilícito), y también respecto de las víctimas indirectas: abrir el art. 7.2 del Reglamento 1215 a estas víctimas, además de generar un forum actoris al permitirles demandar ante los Tribunales de su domicilio, pone en riesgo no solo la idea de proximidad que debe presidir este foro al no existir necesariamente vínculos objetivos con el Estado del domicilio de la víctima indirecta, también el carácter previsible de la respuesta que ofrece esta norma (apdo. 21 STJCE de 11 de enero de 1990, Dumez; o STJCE de 27 de octubre de 1998, Réunion européenne).

5. Un apunte final. Italia no forma parte del Convenio de La Haya de 4 de mayo de 1971 sobre ley aplicable a accidentes de circulación por carretera, de ahí que el Tribunal de Trieste, órgano remitente, se haya cuestionado el alcance del art. 4.1 Roma II 
en este caso. No hubiera sucedido lo mismo de presentarse la demanda ante los Tribunales españoles, al ser España parte del Convenio desde 1987: no siendo este Convenio un "...Convenio(s) celebrado(s) exclusivamente entre dos o más Estados miembros...», en cuyo caso primaría el Reglamento Roma II (art. 28.2 Roma II), los Tribunales españoles hubieran aplicado preferentemente el Convenio de La Haya de 1971 (y no el art. 4.1 Roma II) en tanto en cuanto el Reglamento Roma II «...no afectará a la aplicación de los Convenios internacionales en que sean parte uno o más Estados miembros [...] y que regulen los conflictos de leyes en materia de obligaciones extracontractuales...» (art. 28.1 Roma II). No obstante, y aun cuando la inaplicación en este caso del art. 4.1 Roma II por parte de los órganos jurisdiccionales españoles, la interpretación uniforme que de este precepto hace el TJUE en esta sentencia sí resulta útil en aquellos casos en los que sea necesario identificar la ley aplicable a la responsabilidad extracontractual con base en el art. 4 Roma II respecto de otras materias.

No vamos a entrar, al hilo de lo expuesto, en aquellos problemas que plantea la aplicación de este art. 28 Roma II en relación con el objetivo del legislador europeo de unificar ex Reglamento Roma II las respuestas de ley aplicable en materia de obligaciones no contractuales [objetivo al que tampoco contribuye el hecho de que el legislador europeo no haya conseguido incluir en el ámbito del Reglamento Roma II materias tan importantes en sede de responsabilidad extracontractual como aquellas obligaciones extracontractuales que se deriven de la violación de la intimidad o de los derechos relacionados con la personalidad, en particular, la difamación; art. 1.2.g) Roma II]. Aunque loable la idea de preservar los compromisos internacionales contraídos por los Estados miembros (considerando 36 Reglamento Roma II), la aplicación preferente, salvo denuncia (art. 29 Roma II), de los Convenios específicos con terceros Estados, combinada con el hecho de que no todos los Estados miembros son parte de todos estos Convenios específicos, lo que hace es quebrantar la unificación conflictual y uniformidad de soluciones que persigue el Reglamento Roma II: no todos los Tribunales de los Estados miembros aplicarán las mismas normas de conflicto para determinar la ley aplicable en materia de responsabilidad extracontractual, tal como sucede por daños derivados de accidentes de circulación o en sede de responsabilidad por productos defectuosos, fomentando así el forum shopping.

Javier MASEDA RODRÍGUEZ

Universidad de Santiago de Compostela http://dx.doi.org/10.17103/redi.68.1.2016.3b.08

\section{PRÁCTICA ESPAÑOLA: DERECHO JUDICIAL INTERNACIONAL}

\subsection{Competencia judicial internacional: Reglamento 44/2001}

2016-9-Pr

COMPETENCIA JUDICIAL INTERNACIONAL Y DERECHO APLICABLE.-Contrato individual de trabajo.- Reglamento 44/2001.-Cláusulas sobre jurisdicción y ley aplicable.-Lugar en el que el trabajador desempeña habitualmente su trabajo.

Preceptos aplicados: arts. 18.2, 19 y 21 del Reglamento (CE) núm. 44/2001, art. 8 del Reglamento 593/2008. 


\section{Sentencia del TSJ de Cataluña, Sala de lo Social (Sección 1. ${ }^{a}$ ), núm. 4166/2015,} de 25 de junio. Ponente: Luis Revilla Pérez.

\section{F.: Aranzadi Westlaw, JUR 2015/190642.}

Partiendo de la normativa y jurisprudencia expuesta, es lógico concluir que el lugar en que tengan los demandados su domicilio es el determinante para fijar la competencia internacional en la presente litis, pues, tratándose de empresarios domiciliados en un Estado miembro, serán competentes los tribunales del Estado donde el empresario demandado tenga el domicilio, o a elección del propio trabajador demandante, los tribunales del Estado donde desempeñare habitualmente su trabajo o ante el tribunal del último lugar en que lo hubiere desempeñado, o si el trabajador no desempeñare o no hubiere desempeñado habitualmente su trabajo en un único Estado, ante el tribunal del lugar en que estuviere o hubiere estado situado el establecimiento que hubiere empleado al trabajador, todo ello a salvo de que concurrieran competencias exclusivas (que no son de aplicación a la materia laboral) (arts. 18.1 y 19 Reglamento CE 44/2001), o que las partes hubieran comprometido expresamente su sumisión expresa a los tribunales de un determinado Estado mediante un pacto celebrado después del nacimiento del litigio o, cuando se celebre con anterioridad, permita al trabajador formular demandas ante tribunales distintos de aquellos a los que las reglas del citado Reglamento confieren la competencia (art. 21 Reglamento CE 44/2001 en su interpretación jurisprudencial). [...]

La ley aplicable podrá determinarse, cabe concluir así, basándose en el principio de libertad de elección aunque ello solo en el caso de que el trabajador obtenga el mismo nivel de protección que con la ley aplicable en defecto de elección. En este último caso, el contrato se regirá por la ley del país en el cual o, en su defecto, a partir del cual el trabajador realice su trabajo habitualmente.

Nota. 1. El demandante, extranjero con domicilio en España, trabajó para Ryanair, empresa domiciliada en Irlanda, país este último en el que celebró el contrato de prestación de servicios que debían ser desempeñados en los aviones de la compañía aérea, aeronaves con pabellón irlandés y base en el aeropuerto de Girona. En el contrato se incluía una cláusula de sumisión expresa a los tribunales irlandeses y se determinaba la ley irlandesa como aplicable a la relación laboral. En cuanto al salario del trabajador, era abonado por la empresa en una cuenta bancaria de una entidad de crédito irlandesa, y tanto la cotización como las retenciones fiscales se ingresaban en Irlanda. El trabajador fue despedido por falsificar certificados de un curso de seguridad necesario para operar en el aeropuerto de Girona. Interpuesta demanda de despido improcedente ante el Juzgado de lo Social de Girona, la empresa alegó falta de jurisdicción del Juzgado español, que dictó sentencia desestimando la declinatoria, declaró el despido procedente y estimó parcialmente la reclamación de cantidad ejercitada por el actor en concepto de liquidación de la relación laboral. El Juzgado de instancia interpretó que la excepción de falta de jurisdicción no era sino una maniobra dilatoria por parte de la empresa demandada. Dicha sentencia fue objeto de recurso por la empresa cuyo motivo principal se basaba en la infracción de las normas de competencia judicial internacional.

2. Para proteger al trabajador como parte débil del contrato existen una serie de reglas más favorables a sus intereses, tal y como atestigua el considerando 13 del Reglamento (CE) 44/2001 — que resulta aplicable a los hechos, dado que la demanda se interpuso con anterioridad a la aplicación del Reglamento (UE) 1215/2012 - y la jurisprudencia del Tribunal de Justicia (por todas, STJ de 10 de septiembre de 2015, 
C-47/14, apdo. 43, Holterman). El TSJ comienza citando una sentencia en un caso parejo, la STS de 30 de diciembre de 2013 — cuya similitudes se señalan más adelante- para exponer estas reglas particulares que determinan la eventual competencia judicial internacional de los tribunales españoles en reclamaciones derivadas de contrato de trabajo; todo ello de acuerdo con la interpretación del Convenio de Bruselas de 1968, el Reglamento 44/2001 y el art. 25 LOPJ de 1985. Por un lado, corresponde valorar la cláusula de sumisión a los tribunales irlandeses (art. 21) y, por otro, el resto de criterios de conexión para establecer si alguno otorga competencia a los tribunales españoles (art. 19). De acuerdo con el art. 21, los acuerdos atributivos de competencia deben ser posteriores al nacimiento del litigio o permitir al trabajador formular demandas ante tribunales distintos de los indicados en el art. 19. Pues bien, dado que la cláusula se incluye en el contrato de trabajo y no permite al trabajador formular demandas ante tribunales diferentes (el acuerdo designaba los tribunales del domicilio de la empresa), sería inválida, tal y como aprecia la sentencia.

3. En este punto se debe determinar si la base de Ryanair en el aeropuerto de Girona resulta relevante como criterio de conexión, y para ello es necesario interpretar si la empresa irlandesa posee un establecimiento allí que pueda considerarse domicilio. Hay que partir del concepto de domicilio que recoge el art. 60 R. 44/2001 — «lugar en que se encuentre su sede estatutaria, su administración central o su centro de actividad principal»_ y es fácil colegir que ninguno de esos lugares radica en España. $\mathrm{El}$ art. 18 indica que se considerará la «sucursal, agencia o cualquier otro establecimiento en un Estado miembro» como domicilio únicamente cuando el empresario no tuviere su domicilio en un país de la Unión Europea; por tanto, el establecimiento que posee Ryanair en Girona tampoco puede asimilarse a este concepto, ya que la empresa tiene su domicilio en Irlanda. Así lo atestigua el TSJ, de acuerdo con la STJ de 19 de julio de 2012, C-154/11, Ahmed Mahamdia, con nota de MASEDA RodRíGuEZ, J., REDI, 2013-1, pp. 203-208.

4. La cuestión relevante a los efectos de esta Nota es, pues, determinar el lugar en el que el trabajador habitualmente desempeñó su trabajo. Y lo es porque el TSJ de Cataluña concluye que este lugar es Girona, desvinculándose con ello de la ya citada STS de 30 de diciembre de 2013 que, en un supuesto muy similar (la parte demandada es la misma aerolínea y los trabajadores son auxiliares de vuelo despedidos que tenían su domicilio en España, la empresa impugna la competencia de los tribunales españoles y los contratos de trabajo no se suscribieron en España, existiendo una cláusula de sumisión a los tribunales irlandeses) el TS consideró que los servicios no se habían prestado en territorio español y, por tanto, declaró la falta de jurisdicción de los tribunales españoles para conocer de la demanda de despido. El TSJ fundamenta su decisión en la existencia de «un centro de operaciones que se manifiesta de modo duradero hacia el exterior como la prolongación de una casa matriz», circunstancia esta que habilita «el fuero alternativo electivo» para el trabajador (apdo. 48 del asunto Ahmed Mahamdia ya citado) por la adscripción del trabajador a la base de Girona. No es posible compartir este criterio por dos circunstancias, ambas curiosamente esgrimidas en la propia sentencia: la primera es que el establecimiento de la empresa a efectos del art. 18.2 del Reglamento 44/2001 opera cuando el empresario no tiene su domicilio en un país de la Unión Europea y, como ya se ha expuesto, no es el caso; la segunda es que los servicios como auxiliar de cabina no se prestaban en tierra donde se sitúa la base catalana sino a bordo de las aeronaves de pabellón irlandés, según se desprende de los antecedentes de hecho y de acuerdo con el último párrafo del FJ 5.

5. El contrato de trabajo incluía una cláusula de elección de ley que designaba el Derecho irlandés como aplicable ante cualquier controversia. Las normas de conflicto 
especiales relativas a los contratos individuales de trabajo incluidas en el Reglamento Roma I limitan la libertad de elección de la ley aplicable, ya que el acuerdo de las partes no puede excluir la aplicación de las disposiciones imperativas de la ley que sería aplicable al contrato a falta de elección. La ley aplicable sería la del país en el cual el trabajador realice su trabajo habitualmente (art. 8 del Reglamento Roma I), punto de conexión que coincide con el criterio de determinación de competencia judicial internacional (art. 18 del Reglamento 44/2001). A la luz de la estrecha relación existente entre el Reglamento Roma I y el Reglamento 44/2001 y dado que los citados instrumentos normativos utilizan conceptos idénticos es preciso garantizar la coherencia y la interpretación más uniforme posible (apdo. 32 Conclusiones Abogado General en el asunto C-29/10, Koelzsch). Para respetar dicha coherencia es preciso que la ley española sea la aplicable, ya que el TSJ considera que el trabajo se prestó en territorio español, como así recoge la sentencia.

6. En fin, la interpretación de la conexión del lugar habitual del trabajo hubiera sido acertada si los servicios se hubiesen prestado en diversos Estados, quizás teniendo en cuenta las rutas por las que habitualmente discurría el trabajador, ya que podría haberse identificado la base de operaciones en España como el lugar en el que este organizaba sus actividades, el centro efectivo de su actividad profesional (STJCE de 9 de enero de 1997, C-383/95, Rutten, con nota de Zabalo Escudero, E., REDI, 1997-2, pp. 283-286) o el lugar en el que cumplía principalmente sus obligaciones (STJCE de 13 de julio de 1993, C-125/92, Mulox), pero no nos encontramos ante esos supuestos.

\author{
Carmen María García Mirete \\ Universidad de Alicante \\ http://dx.doi.org/10.17103/redi.68.1.2016.3b.09
}

2016-10-Pr

COMPETENCIA JUDICIAL INTERNACIONAL EN MATERIA DE INFRACCIÓN DE DERECHOS MORALES DE AUTOR.-Art. 22.3 LOPJ.-Determinación del lugar de la infracción.-Asimilación a los derechos de la personalidad a efectos de competencia.-Competencia de los tribunales del domicilio del demandante como lugar del centro de los intereses principales del autor.

Preceptos aplicados: art. 22.3 LOPJ.

Auto Audiencia Provincial de Barcelona (Sección 15. a), núm. 32/2015, de 12 de marzo. Ponente: Juan F. Garnica Martín.

\title{
F.: Aranzadi Westlaw, JUR 2015/259548.
}

(M) interpuso demanda contra... una entidad pública de nacionalidad qatari, y contra el Estado de Qatar solicitando, al amparo de lo establecido en la legislación sobre propiedad intelectual, frente a ambas demandadas que se declarara que la actora es la autora de una obra de diseño denominada farola... y que las demandadas habian vulnerado los derechos morales de divulgación, paternidad e integridad de la actora sobre su obra al encargar la construcción de referido modelo de farola y colocarlo en una de las calles de Doba (Qatar). También solicitó que se condenara a las demandadas a cesar en su conducta ilícita procediendo a la retirada a su costa de la Avenida Al Waab de Doha las farolas copiadas y falsificadas de su obra y a indemnizarle, en concepto de daños morales, con la cantidad de 100.000 euros. 
[...] 18. Pero, en cualquier caso, creemos que es razonable la alegación de la recurrente de que la norma de nuestro derecho interno, que sustancialmente es idéntica a la contenida en el artículo 5.3 RBI (actualmente en el artículo 7.2 RBI-bis), debe ser interpretada en sintonía con esos preceptos.

[...] 34. Ello nos lleva a considerar que es razonable aplicar nuestra norma interna en sintonía con la doctrina establecida en la Sentencia del Tribunal Europeo de 25 de octubre de 2011 (casos eDate y Martínez), al estimar que es la que mejor se acomoda a la naturaleza de los derechos objeto del presente proceso. En suma, estimamos que el concepto "hecho ocurrido en territorio español» incluye el supuesto de que el daño se haya "manifestado en nuestro territorio». Y a su vez, este último concepto, cuando está referido a los derechos morales de autor, permite situar como lugar de manifestación del daño el territorio español, porque es en el mismo donde se produce una doble circunstancia: i) Aquí tienen protección los derechos que se afirman infringidos. ii) Y también en nuestro territorio se produjo el proceso creativo que dio lugar al nacimiento de esos derechos, por ser el lugar en el que desarrolla la actora su actividad creativa.

Nota. 1. Es conocido que el Tribunal de Justicia ha puesto de relieve en varias sentencias que su jurisprudencia eDate Advertising en materia de derechos de la personalidad no es aplicable a las reclamaciones relativas a derechos de propiedad industrial e intelectual (véanse SSTJUE de 19 de abril de 2012, C-523/10, Wintersteiger; y de 3 de octubre de 2013, C-170/12, Pinckney). Por su parte, en relación con los derechos morales de autor resulta relevante que el Tribunal de Justicia todavía no se ha pronunciado en demandas fundadas en su vulneración, por lo que respecto de los derechos morales cabe sostener que la cuestión puede resultar controvertida. La eventual aplicación de la jurisprudencia eDate Advertising a estas reclamaciones resultaría de gran importancia práctica en la medida en que facilitaría la reclamación por parte de la víctima (demandante) ante los tribunales de su propio domicilio por el conjunto del daño. En este contexto, presenta un singular interés el Auto de 12 de marzo de 2015 de la Sección 15. ${ }^{a}$ de la Audiencia Provincial de Barcelona, si bien en relación con la aplicación de las normas de competencia internacional de fuente interna.

2. Dicho Auto va referido a una demanda de una autora española contra una empresa qatarí y el Estado de Qatar relativa a «que las demandadas habían vulnerado los derechos morales de divulgación, paternidad e integridad de la actora sobre su obra al encargar la construcción del referido modelo de farola» (según parece en China y Turquía) «y colocarlo en una de las calles de Doha» (Qatar) (apdo. 1 del Auto), procediendo a solicitar la retirada de las farolas en Doha así como una indemnización en concepto de daños morales.

La Audiencia Provincial de Barcelona concluye que los tribunales españoles tienen competencia judicial internacional para conocer de la demanda, básicamente por considerar razonable aplicar el art. 22.3 LOPJ — que exige que el hecho del que deriva la responsabilidad «haya ocurrido en territorio español»- en sintonía con la doctrina del Tribunal de Justicia en su Sentencia eDate Advertising relativa a derechos de la personalidad (apdos. 33-34 del Auto). En consecuencia, la Audiencia Provincial estima el recurso de apelación contra la resolución del Juzgado de lo Mercantil núm. 2 de Barcelona, de 9 de octubre de 2013, que revoca, desestimando la declinatoria ejercitada por las demandadas (acerca de la resolución de primera instancia, véase HeREDIA Cervantes, I., "Competencia judicial internacional y derechos morales de propiedad intelectual», publicado en el Diario La Ley, núm. 8386, de 26 de septiembre de 2014).

3. Sin entrar ahora a valorar en qué medida el criterio adoptado por el Tribunal de Justicia en su Sentencia eDate Advertising puede resultar relevante en relación con 
la vulneración de derechos morales de autor en Internet, la argumentación del Auto reseñado de la Audiencia Provincial de Barcelona se presta a una valoración crítica. En este contexto, resulta apropiado poner de relieve ciertas carencias en su contenido, con el objetivo de evitar una mayor incertidumbre acerca de cuál es el marco jurídico del tratamiento de los aspectos de DIPr de los derechos morales de autor en nuestro ordenamiento.

A este respecto, la reciente LO 7/2015, de 21 de julio, por la que se modifica la LO 6/1985, de 1 de julio, del Poder Judicial, no altera sustancialmente la situación, si bien la norma relevante se encuentra tras la reforma en el art. 22 quinquies b) LOPJ, que en materia de obligaciones extracontractuales atribuye competencia a los tribunales españoles «cuando el hecho dañoso se haya producido en territorio español».

4. Una valoración crítica del Auto no impide apreciar que resulta razonable el enfoque adoptado por la Audiencia en lo relativo a que la norma del art. 22.3 LOPJ debe ser interpretada en sintonía con la norma del art. 7.2 RBI bis (art. 5.3 RBI), por lo que es apropiado acudir a la jurisprudencia del Tribunal de Justicia relativa al fuero del lugar del daño (apdos. 18 y ss. del Auto). Ahora bien, precisamente desde esta perspectiva llama la atención que la Audiencia pretenda fundamentar su decisión en los argumentos recogidos en los apartados 33 y 34.

Por una parte, en el apartado 33 del Auto, para extender la doctrina de la Sentencia eDate a los derechos morales de autor en la interpretación del art. 22.3 LOPJ, afirma la Audiencia que: «La razón por la que esa asimilación es posible creemos que radica en la similitud de los derechos morales de autor con los derechos de la personalidad en cuanto a la dificultad de situar en el espacio su infracción a efectos de determinar donde se manifiesta el daño. Es razonable situar esa manifestación del daño en el lugar en el que el proceso creativo ha tenido lugar y en el que, a su vez, tienen protección los derechos supuestamente infringidos».

Sin embargo, en la Sentencia eDate Advertising esa dificultad de localización derivaba de que las actividades infractoras objeto de los litigios principales se llevaban a cabo a través de Internet, de modo que en realidad excluye semejante dificultad de localización esté presente en situaciones en las que la actividad infractora se ubica de manera precisa en un lugar. Por otra parte, el contraste entre las conclusiones del abogado general y la sentencia del Tribunal de Justicia en el asunto Hejduk — que el Auto menciona-, pone de relieve cómo la dificultad — que en principio solo surge en el contexto de actividades realizadas a través de Internet- de localizar dónde se produce el daño no es motivo para una interpretación del fuero del art. 7.2 RBI bis diferente a la consolidada en relación con las infracciones de derechos de autor.

5. Por otra parte, en el apartado 34 del Auto, la Audiencia insiste en que el resultado que alcanza es producto de proyectar sobre el caso que tiene planteado la jurisprudencia del Tribunal de Justicia en materia de derechos de la personalidad en el asunto eDate Advertising, como se desprende del extracto del Auto reproducido al inicio de esta nota.

Ahora bien, en la Sentencia eDate Advertising el Tribunal de Justicia dejó claro de manera reiterada que la solución específica que permite a la víctima reclamar ante los tribunales de su centro de intereses solo resulta de aplicación cuando la actividad supuestamente infractora se produce a través de Internet (véanse los apdos. 45 y ss. así como el fallo de la Sentencia eDate Advertising; a modo de ejemplo, en su apdo. 48, afirmó el Tribunal de Justicia: «...Habida cuenta de que la repercusión de un contenido publicado en Internet sobre los derechos de la personalidad de una persona 
puede ser apreciada mejor por el órgano jurisdiccional del lugar en el que la supuesta víctima tiene su centro de intereses, la atribución de competencia a dicho órgano jurisdiccional corresponde al objetivo de una buena administración de la justicia...»).

En consecuencia, a la luz de la jurisprudencia actual del Tribunal de Justicia la posibilidad de plantear la eventual extensión de esta doctrina a las reclamaciones relativas a derechos morales de autor parece que solo podría suscitarse en relación con actividades desarrolladas a través de Internet.

6. Por último, aunque se trata de una cuestión no abordada en el Auto, cabe recordar que el carácter territorial de los derechos de autor, incluidos los derechos morales, determina que la ley aplicable a su protección en nuestro sistema de DIPr sea la del país para el que se reclama la protección (art. 8 del Reglamento Roma II, en la medida en que desplaza al art. 10.4 CC que incorpora la misma solución), de modo que no tiene por qué coincidir con la española cuando los tribunales españoles tengan competencia para conocer de la infracción de derechos de autor en el extranjero. La territorialidad de los derechos morales de autor constituye un elemento diferenciador de gran importancia con respecto a lo que es propio de los derechos de la personalidad, pues en relación con los derechos morales de autor no será determinante para establecer la ley aplicable el art. 10.9 CC sino el art. 8 RRII. Por ejemplo, cuando la violación de los derechos de autor resulta de la fabricación o de la utilización de un producto en el extranjero, cabe entender que la ley del país para el que se reclama la protección es típicamente la ley del país en el que la fabricación o la utilización del producto han tenido lugar.

Pedro Alberto DE Miguel Asensio Universidad Complutense de Madrid http://dx.doi.org/10.17103/redi.68.1.2016.3b.10

\subsection{Competencia judicial internacional: Reglamento $2201 / 2003$}

2016-11-Pr

COMPETENCIA JUDICIAL INTERNACIONAL.-Divorcio, responsabilidad parental y alimentos.-Litispendencia.-Comunicaciones judiciales directas.- Remisión del asunto al juez mejor situado.

Preceptos aplicados: arts. 3, 8, 15 y 19 del Reglamento 2201/2003; art. 3.a) y c) del Reglamento 4/2009.

Auto Audiencia Provincial de Barcelona (Sección 18. ${ }^{a}$ ), núm. 161/2015, de 20 de mayo. Ponente: Francisco Javier Pereda Gámez.

\section{F.: Aranzadi Westlaw, AC 2015/789.}

[...] tenemos datos que permiten determinar el objeto y la causa de la demanda interpuesta en Polonia, pero no demuestran, en particular la competencia de ese órgano...

[...] el juez polaco, llamado a resolver la cuestión de competencia planteada, ha optado por suspender las actuaciones hasta el final de este proceso, cuando debería haber decidido sobre la competencia, al ser el tribunal al que se presentó la primera demanda (art. 19 del Reglamento). Ello implica una admisión inicial de su falta de competencia, 
aunque no la haya declinado formalmente, como exige el Reglamento. A mayor abundamiento entendemos que podemos resolver sobre la competencia porque consideramos no existe litispendencia, al concurrir a favor del tribunal español los fueros del art. 3 del Reglamento.

[...] Del contenido de la demanda presentada en Polonia se desprende de forma manifiesta que dicha demanda no contiene ningún elemento que permita justificar la competencia..., por lo que este segundo órgano jurisdiccional puede estimar que no existe litispendencia...

[...] A pesar de lo expuesto, concurre la circunstancia extraordinaria del art. 15 del Reglamento: el menor vive en Polonia desde el año 2012, donde ha crecido y tiene su entorno actual, todo ello con la aquiescencia del padre, que en medidas provisionales ha aceptado esta situación y el reconocimiento de un régimen de visitas a su favor. Concurren las circunstancias contempladas en los apartados a), b) y d) del art. 15 y la remisión puede acordarse de oficio en tanto concurre el consentimiento de una de las partes que mantiene la competencia de los Tribunales polacos.

Ante los Tribunales polacos ya consta presentada la demanda por lo que el plazo de seis semanas que establece el art. 15.5 debe computarse desde la comunicación de la remisión.

Nota. 1. El 19 de octubre de 2012 una ciudadana presenta en Lublin (Polonia) una demanda de divorcio. El 15 de noviembre el esposo plantea idéntica demanda en España, solicitando la guarda y custodia de la hija común, con visitas para la madre, prohibición de salida del territorio nacional y fijación de alimentos por el Juzgado. La familia había residido en Barcelona hasta la marcha, presuntamente ilícita, de la madre junto a la menor en marzo de 2012. Con carácter previo, en fecha que no se concreta en el Auto de la Audiencia, pero por lo que parece es anterior al 19 de octubre, el esposo había solicitado medidas provisionales previas en España.

2. La situación analizada se presenta, prima facie, como una situación de litispendencia. Así lo había apreciado el Auto recurrido en apelación, de 28 de noviembre de 2013, que había sobreseído el procedimiento estimando la excepción de litispendencia. Dicho auto es recurrido por el esposo, quien tomando en consideración la petición de medidas provisionales previas, sostiene que el pleito más antiguo es el pleito español.

3. Con profusa cita de la sentencia del Tribunal de Justicia de 9 de noviembre de 2010 (Purrucker I) la Audiencia resuelve que las medidas provisionales no generan litispendencia y que, por tanto, la demanda se había planteado en primer lugar en Polonia. Surgen, sin embargo, dudas respecto a la competencia del juez polaco, pues la esposa había planteado la demanda cuando no habían transcurrido seis meses desde que dejó España. Entiende, asimismo, la Audiencia que la niña residía en esos momentos en Barcelona, pese a haber sido desplazada por su madre a Polonia. A través de la Red Judicial civil europea se pide información al juez polaco, quien en lugar de decidir acerca de su competencia, tal y como le correspondía según el art. 19 del Reglamento, decide suspender hasta que concluya el procedimiento español.

4. A raíz, presuntamente, de la demanda de información de la Audiencia, se genera una situación anómala y no prevista por el Reglamento 2201/2003, el Tribunal ante el que se ha interpuesto la demanda en primer lugar, suspende a la espera de lo que decida el Tribunal llamado en segundo término. Esto equivale, y así se desliza en el texto de la sentencia comentada, a la admisión de una suerte de cuestión de com- 
petencia. El Tribunal polaco prescinde del criterio del prior temporis y parece ceder la decisión a quien tiene mayor fundamento para ejercer la competencia y la reclama para sí.

5. A partir de ahí el razonamiento de la Audiencia es heterodoxamente eficaz. Se llega a la conclusión de que el Tribunal polaco carece de competencia, esto es, se decide acerca de la competencia de un tribunal extranjero, lo que, en principio, podría conceptuarse como una injerencia en el funcionamiento de un poder judicial extranjero. Ello implicaría la atribución del asunto a la jurisdicción española. Pero, se corresponde a la deferencia mostrada por el juez polaco, reconociendo, a su vez, que los tribunales polacos son los mejor situados para resolver, en virtud de la proximidad, acerca de la menor. Esto es, se resuelve en atención únicamente a intereses privados, lo que, sin lugar a dudas es un fruto maduro de la filosofía que sustenta la creación de un espacio judicial común.

6. El diálogo entablado por dos tribunales europeos permite llegar a la solución que en mayor medida responde al interés superior del menor. Influye y así se resalta en la sentencia la aquiescencia del padre. Por tanto, lo que sorprende en este caso, es que no hayan sido los progenitores quienes se decidieran por los tribunales de uno $\mathrm{u}$ otro lugar. Salvo claro está, que la aquiescencia del padre no fuera en realidad tal, sino únicamente la aceptación de unas determinadas condiciones con tal de poder seguir viendo a su hija. Otras cuestiones dudosas son la aplicación del mecanismo de remisión del asunto al juez mejor situado respecto a la totalidad de las cuestiones planteadas cuando el Reglamento solo la prevé en materia de responsabilidad parental.

7. Pero a pesar de estas dudas y de otras que pudieren plantearse, esta sentencia sorprende por la naturalidad con la que dos tribunales de Estados distintos confían el uno en el otro y llegan a una solución ajustada al espíritu de la cooperación civil europea.

\author{
Cristina GonZÁLEZ BEILFUSS \\ Universidad de Barcelona \\ http://dx.doi.org/10.17103/redi.68.1.2016.3b.11
}

\title{
2.3. Reconocimiento y ejecución de resoluciones extranjeras
}

2016-12-Pr

EXEQUÁTUR.-Legitimación de la actora en concepto de heredera.-Naturaleza pública o privada de la condena a Mutua de Accidentes.-Régimen de reconocimiento de la LEC: causas de denegación.-Foros exclusivos

Preceptos aplicados: arts. 395 y 1.695 del CC; art. 954 LEC; arts. 76, 66 y 68 del Reglamento 44/2001; arts. 55 y 1.2 del Convenio de Bruselas de 1968; art. 25.3 LOPJ.

Auto de la AP de Santander (Sección 2. ${ }^{a}$ ), de 24 de septiembre de 2015. Ponente: José Arsuaga Cortázar.

\section{F.: Aranzadi Westlaw, JUR 2015/269852.}

[...] La parte recurre con un argumento - común en este punto al sostenido por la otra parte que también recurre-, como antes se ha explicado, que se relaciona con la 
alegada infracción del orden público procesal español sobre la base de dos motivos: de un lado, la competencia exclusiva de los tribunales españoles en materia de seguridad social, de forma que el reconocimiento no sería posible por infracción de las condiciones 1. ${ }^{a}$ y 3. ${ }^{a}$ del art. 954 1881; del otro, la infracción del orden público (art. 954.3 LEC 1881) por ausencia suficiente de garantías relativas a la audiencia y defensa o a la actividad probatoria practicada. Solo la Mutua Montañesa introduce como motivos la infracción de las condiciones 2. ${ }^{a}$ y $4 .^{a}$ del art. 954.

En consecuencia, la valoración del primer y más trascendente motivo del recurso - a la sazón "1. $\left.{ }^{a}\right)$ Que la ejecutoria haya sido dictada a consecuencia del ejercicio de una acción personal» o que «3. $\left.{ }^{a}\right)$ La obligación para cuyo cumplimiento se ha procedido sea lícita en España»- ha de significar, en sentido negativo, que no habrá de otorgarse el reconocimiento a la sentencia que hubiera sido dictada sobre una materia excluida del tratado internacional de aplicación -Convenio de Bruselas de 1968- por ser de competencia exclusiva de los tribunales españoles [...].

Nota. 1. El AAP de Santander que nos ocupa tiene su origen en el recurso de apelación interpuesto contra el Auto del Juzgado de 1. ${ }^{a}$ Instancia núm. 3 de Santander de 2 de octubre de 2013, en el que se concede el reconocimiento y exequátur de una sentencia portuguesa dictada el 14 de diciembre de 1998, por el Tribunal do Trabahlo de Vila Real. El recurso se interpone, por un lado, por la Mutua Montañesa y, por otro, por los integrantes del Consejo de Administración de Rotella Forestal S. A. La sentencia objeto del controvertido reconocimiento, condenaba a susodicha entidad a abonar una pensión anual y vitalicia (además de otros subsidios) en concepto de indemnización a doña Magdalena por fallecimiento en accidente laboral de su hijo (trabajador de mencionada entidad) del que dependía económicamente. Y extiende la misma condena a la Mutua Montañesa, en calidad de entidad colaboradora de la Seguridad Social (arts. 68 y 115 LGSS), como mutua de accidentes para disponer de las prestaciones que por ley se establezcan. Fallecida la beneficiaria, su hija, solicita su reconocimiento y ejecución en España en calidad de heredera de la titular del crédito.

2. Los recursos contra el Auto de Instancia se fundamentan en dos motivos esenciales. El primero basado en la falta de legitimación de la solicitante del exequátur para actuar en nombre y representación de la comunidad hereditaria formada al fallecimiento de doña Magdalena, no prospera y se desestima correctamente. La actora, como miembro de la comunidad hereditaria, está plenamente legitimada para actuar cuando se trate de salvaguardar la existencia o el valor del patrimonio individual o alguno de sus elementos (arts. ex 395 y 1.695.3 CC) siempre que sea en beneficio de la masa común. El segundo, compartido por ambos recurrentes, se basa en la infracción de los requisitos establecidos en el art. 954 Ley de Enjuiciamiento Civil de 1881 (LEC) para lograr el reconocimiento.

3. Antes de analizar dichos requisitos, lo primero a dilucidar es el régimen legal que debemos aplicar a la solicitud del reconocimiento. La Audiencia aplica el régimen común de reconocimiento de la LEC (arts. 951-958) tal y como interpelan las partes, aludiendo a una argumentación que, si bien no está mal construida, carece de los cimientos básicos para sustentarse y deja entrever las lagunas que preexisten tanto a nivel europeo como interno en torno a la naturaleza pública o privada de la Seguridad Social.

En un primer momento, por razones de índole temporal, queda descartada la aplicación de la nueva Ley de Cooperación judicial en Materia civil, que se aplicará «a las demandas de exequátur que se presenten con posterioridad a la entrada en vigor 
de la ley, con independencia de la fecha de la resolución extranjera» (DT única). Y la aplicación del Reglamento 44/2001 en el que las reglas de reconocimiento no serán de aplicación a las resoluciones dictadas con anterioridad a su entrada en vigor; es decir, antes del 1 de marzo de 2002 (arts. 76 y 66.1 RBI). Sin embargo, desde el punto de vista temporal se podría recurrir al Convenio de Bruselas de 1968, sustituido por el Reglamento (art. $68 \mathrm{RBI}$ ), pues será aplicable a las solicitudes de reconocimiento ante un Estado parte de una resolución de otro Estado parte posterior a su entrada en vigor (art. 55 CB 1968), requisito que se cumple en tanto España y Portugal se adhieren al mismo mediante el Convenio de San Sebastián de 1989.

4. Cuestión distinta es la subsunción del supuesto que nos ocupa dentro del ámbito de aplicación material del Convenio de Bruselas de 1968 (CB), y es aquí donde reside la clave para delimitar su aplicabilidad respecto del régimen común de reconocimiento estipulado en la LEC y reclamado por las partes; pero también donde afloran una serie de incógnitas bajo las que subyace un tema todavía sin resolver ni por la jurisprudencia ni por la doctrina y que se extiende tanto a nivel europeo como interno. En efecto, el ámbito material del CB, art. 1, se aplica a las cuestiones litigiosas que tengan carácter civil o mercantil, independientemente del órgano jurisdiccional del que procedan. Queda excluida, entre otras materias, de manera general la Seguridad Social. El TJUE ha tenido la ocasión de definir estos límites materiales (STJCE de 14 de octubre de 1967, asunto 29/76, LTU/Eurocontrol; STJCE de 16 de diciembre de 1980, asunto 814/79, Pays Bas/Rüffer o STJCE de 21 de abril de 1993, asunto C-172/91, Sonntag) pero no se ha pronunciado en lo que a la Seguridad Social respecta. Podríamos pensar que la Seguridad Social se extrae de su ámbito de aplicación en cuanto pertenece al ámbito de Derecho público y está marcada por la acción imperativa del Estado y la acción de organismos estatales. Sin embargo hay países en los que se encuentra comprendida en una zona marginal situada entre el Derecho privado y el Derecho público (véase Informe P. Jenard sobre el Convenio de Bruselas de 1968, versión española DOCE de 28 de julio de 1990, C 189, p. 133) lo que nos hace plantearnos su naturaleza hibrida, acentuado las dificultades inherentes a su delimitación.

De hecho, esa no fue la razón fundamental para su exclusión del CB sino la necesidad de sortear solapamientos con los trabajos que se desarrollaban por la Comunidad Económica Europea con origen en el art. 51 del Tratado de Roma y con los Convenios en materia de Seguridad Social, ya fueran bilaterales o fruto de otras organizaciones internacionales como la Organización Internacional del Trabajo. Al tratarse de una materia en constante evolución resultaba difícil definirla de manera expresa en el CB sobre todo cuando según el art. 117 del Tratado de Roma, la armonización de los regímenes de seguridad social figuraba entre los objetivos de la Comunidad (véase Informe P. Jenard, op. cit., p. 33). A pesar de ello podría servirnos de orientación el Convenio núm. 102 de la OIT de 28 de junio de 1952 sobre normas mínimas de Seguridad Social, en tanto integra una tabla comparativa de los regímenes de la Seguridad Social de los Estados miembro de las Comunidades Europeas, entre los que se incluyen: atención médica, indemnizaciones por enfermedad, prestaciones de invalidez, prestaciones de desempleo y prestaciones como la que nos ocupa en el presente caso derivadas de accidentes de trabajo. También podría sernos útil la definición del Reglamento núm. 3 del Consejo relativo a la Seguridad social de los trabajadores migrantes, aunque se corresponde con la del Convenio 102 de la OIT.

Pero dejando de lado la controvertida cuestión sobre la naturaleza pública o privada de la Seguridad Social, al concretar el objeto de la presente sentencia vemos que se refiere a la obligación de pagar una prestación vinculada a un accidente de trabajo 
y ello podría considerarse materia ligada a la Seguridad Social (en determinadas ocasiones) lo que supondría su definitiva exclusión del ámbito de aplicación del CB, y el planteamiento de la potencial aplicación de la LEC, tal y como hacen los tribunales. Tal conclusión solo sería válida en lo que a la condena de la Mutua Montañesa respecta, de acuerdo a la cobertura que proporciona como entidad colaboradora de la Seguridad Social, y no a la acción que de forma acumulada se ejercitó contra el empleador para obtener una indemnización por accidente; pues su relación con la beneficiaria se integrará dentro de la responsabilidad civil derivada de un contrato de trabajo. Consecuentemente, tal y como hace la AP, resultan dos regímenes distintos para resolver el recurso planteado aplicables a la Mutua Montañesa y al empleador respectivamente

5. De hecho se estima el recurso de la Mutua Montañesa pero no el del Consejo de Administración de la empresa empleadora —en el que no vamos a entrar- - Y se hace acudiendo al régimen común español de reconocimiento y exequátur contenido en el Libro II, Título VIII, Sección 2. ${ }^{\text {a }}$ de la LEC para las resoluciones judiciales extranjeras dictadas en procedimientos contenciosos y en materia de Derecho privado. ¿A la sazón, no deberíamos plantearnos de nuevo el problema en torno a la delimitación material de la LEC y a la subsunción de la Seguridad Social en su ámbito de aplicación? Sabemos que el régimen contenido en la LEC se reduce a decisiones judiciales en materia civil, mercantil y laboral ¿la Seguridad Social se encuentra integrada en el orden laboral? La Audiencia no dice nada al respecto pero según el difícil camino trazado hasta el momento todo apunta a su exclusión. La Ley de Cooperación judicial civil nos da alguna pista acerca de a qué se refiere con «orden laboral» y en un interno de esclarecer el problema parece decantarse únicamente por la responsabilidad civil derivada de contratos de trabajo (art. 1 LCJC), excluyendo la Seguridad Social.

6. Dejar sin resolver el problema inicial en torno a la naturaleza de la Seguridad Social lleva a la Audiencia a adoptar una postura carente de fundamento mediante la que fuerza una interpretación amplia del régimen general de reconocimiento en el que mete con calzador como causa de posible de denegación del mismo el control de la competencia exclusiva de los Tribunales españoles en materia de Seguridad Social otorgado por el art. 25.3 LOPJ.

El régimen común de reconocimiento gira en torno al art. 954 de la LEC que diseña un régimen de condiciones mínimas vinculadas a exigencias constitucionales o sustantivas (orden público, garantías procesales; control del competencias) y/o requisitos formales y de congruencia con el sistema jurídico (cosa juzgada, autenticidad). En su enunciado no existe una reglamentación directa y específica del control de la competencia judicial internacional aunque la jurisprudencia del TS la ha venido exigiendo con el objetivo de garantizar el control y el respeto de las competencias atribuidas con carácter exclusivo a los Tribunales del foro, ahora bien refiriéndose al art. 22 LOPJ (véase FERnÁNDEz RozAs, J. y SÁnChez LoREnzo, S., Derecho Internacional Privado, 1. ${ }^{a}$ ed., Madrid, Civitas, 1999, p. 300). Sin embargo, esa es la razón en la que se basa la AP para estimar el recurso de la Mutua y dejar sin efecto el Auto de primera Instancia en lo que a ella respecta, sirviéndose de esta vía de denegación y dotando al art. 25.3 de la LOPJ de la consideración de foro exclusivo. El art. 25.3 LOPJ prevé un foro específico en materia de protección social, en concreto en lo relativo a la reclamación de las prestaciones de Seguridad Social, que podrán ser ejercitadas ante los órganos jurisdiccionales españoles cuando se interpongan frente a entidades españolas o con domicilio, agencia, delegación o cualquier otra representación en España. La determinación de la competencia de los Tribunales españoles se basa en la nacionalidad de la entidad demanda (ente gestor de la SS o empresa) que debe ser la española 
(STSJ Andalucía, Málaga, de 21 de mayo de 1999). Pero no nos parece argumento suficiente para integrarlo en los foros exclusivos. El principio de libre circulación de personas se vería gravemente debilitado si los trabajadores desplazados (cada vez más) estuvieran obligados a prescindir del foro del lugar de prestación de servicios en aras a asegurar el reconocimiento de una resolución emitida en un Estado distinto al de la nacionalidad de la Entidad que les debe pagar una determinada prestación. La tendencia europea es precisamente la inversa; y así se vislumbra por ejemplo en el art. 8 de la Directiva 2008/94/CE, de 22 de octubre, relativa a la protección de los trabajadores asalariados en caso de insolvencia del empresario. Muestra de todo lo anterior podemos concluir la apremiante necesidad de delimitar no solo la naturaleza de la Seguridad Social, sino también el alcance del foro integrado en el art. 25.3 de LOPJ que, a pesar del incremento de los supuestos relacionados con la movilidad de los trabajadores, no ha sido modificado por la nueva LOPJ.

Nerea Magallón Elósegui

Universidad de Deusto

http://dx.doi.org/10.17103/redi.68.1.2016.3b.12

\section{PRÁCTICA ESPAÑOLA: DERECHO CIVIL INTERNACIONAL}

\subsection{Determinación de la ley aplicable: filiación natural}

2016-13-Pr

FILIACIÓN.-Acción de reclamación de la filiación paterna.-Competencia judicial internacional de los Tribunales españoles.-Derecho aplicable: Derecho civil catalán por coincidir con la residencia habitual del menor--Revocación sentencia de instancia: falta de impugnación de la filiación inscrita; protección incorrecta del interés del menor.

Preceptos aplicados: arts. 9.4 y 13.2 CC; art. 235-19 CC catalán.

Sentencia de la AP de Barcelona (Sección 12. ${ }^{\text {a) }}$, núm. 477/2015, de 1 de julio. Ponente: Sr. D. Pascual Ortuño Muñoz.

\section{F.: Aranzadi Westlaw, AC 2015/1437.}

[...] Por lo que se refiere al segundo de los presupuestos del enjuiciamiento que invocan los recurrentes, que es el de la ley aplicable, tampoco existe norma internacional que obligue a España a aplicar el derecho extranjero. El artículo 9 del Código Civil (LEG 1889, 27) en su párrafo 4) establece que el carácter y contenido de la filiación y las relaciones paterno filiales se regirán por la ley personal del hijo y, si esta no pudiera determinarse, por la residencia habitual. En este caso y como ya se ha expresado en el párrafo precedente, no se ha acreditado de forma incuestionable la ley personal del hijo, que sería la de su nacionalidad, por cuanto consta que si bien la madre es nacional de Lituania, tiene su residencia en España desde el año 2000, y el padre es de nacionalidad española. Por otra parte el actor (que pretendió con la demanda el reconocimiento de su paternidad sobre el hijo) ostenta la nacionalidad brasileña, por lo que existiría también y eventualmente un derecho del menor a optar por la nacionalidad del mismo en caso de que prosperase la acción ejercitada, lo que determina que haya de enjuiciarse este caso con arreglo a la ley de la residencia habitual, que es la española. 
Al existir en España diferentes leyes que regulan esta materia, por el principio de territorialidad establecido en el artículo 13.2 del Código Civil español y en lo que dispone el artículo 14.1 del Estatuto de Autonomía de Catalunya, corresponde aplicar las normas del Código Civil de esta Comunidad Autónoma. En concreto es de aplicación la normativa recogida en la Sección I del Capítulo V del Título III del Libro II del CCCat [...].

Nota. 1. La SAP de Barcelona (Sección 12. ${ }^{\text {) }}$ objeto de esta nota presenta el interés de resolver con pulcritud un litigio en el que en un litigio sobre determinación de filiación con elemento extranjero lo que se enmascara tal vez es un intento del demandante en instancia de acogerse a las ventajas que ofrece el ordenamiento español a nacionales de países terceros para entrar y residir en España. En el sustrato fáctico se trataba de un menor nacido en Barcelona e inscrito en Registro civil español como hijo biológico de una nacional lituana y un nacional español, todos residentes en Barcelona. En instancia un nacional brasileño había planteado una acción de reclamación de dicha filiación sin solicitar la impugnación de la filiación paterna inscrita. Habiendo prosperado la reclamación por Sentencia del Juzgado de Primera Instancia núm. 8 de Manresa, los demandados en instancia son los recurrentes ante la Audiencia de Barcelona. Como fundamento del recurso invocan infracción de las normas de DIPr español al cuestionar la competencia judicial de los Tribunales españoles; al tiempo solicitan que no se declare aplicable la ley española sino la de Lituania —en el que el plazo de prescripción de las acciones se extiende a un año frente a la imprescriptibilidad en el ordenamiento español—; la ausencia de impugnación de la filiación paterna inscrita en el registro y, por último la vulneración del derecho del menor al no haber sido oído en una decisión que le afecta la competencia judicial de los tribunales lituanos, son los motivos que fundamentan el recurso.

2. Desde la óptica del DIPr la SAP de 1 de julio de 2015 es didáctica sobre el sistema instaurado en cuanto a las acciones de filiación por el juego conjunto de los arts. 22... LOPJ 1985 y el art. 9.4 CC la regla de conflicto en la versión consolidada tras la reforma operada por LO 1/996, de 15 de enero, de Protección jurídica del menor. Recuerda, en primer lugar, la competencia judicial internacional de los Tribunales españoles cuando el hijo posea la residencia habitual en España al tiempo de la interposición de la demanda, descartando que puedan ser competentes los de Lituania aunque el menor posea dicha nacionalidad. Advierte, de paso, que la aplicación de las normas lituanas requiere la residencia de la madre en aquel país, no siendo así, además de que el menor posee en todo caso la nacionalidad española transmitida por el padre registral.

3. En el plano del Derecho aplicable sí tienen interés dos elementos de la argumentación. En primer lugar, resulta interesante el salto de la primera a la segunda conexión: pese a que el menor posee la nacionalidad española, al estar condicionada la nacionalidad por el resultado de la acción de filiación y dado que el reclamante posee la nacionalidad brasileña que eventualmente transmitiría al menor, decide la AP no comprometer la primera conexión y proponer la aplicación de la ley española por ser la coincidente con la residencia habitual del menor. Es una solución correcta habida cuenta de la implicación de la nacionalidad en las acciones de estado. Confirma así - como se interpretaba en la legislación anteriormente vigente- que la segunda conexión debía entrar en escena cuando no pudiera determinarse la ley nacional en aras de la consecución del objetivo material —el establecimiento de la verdad biológica-. Esto ha cambiado con la Ley 26/2015, de 28 de julio, de Modificación del sistema de protección a la infancia y a la adolescencia, no solo al invertirse el orden de las conexiones colocando en primer término la residencia habitual del menor; también al 
subordinar expresamente la aplicación de la segunda y tercera conexiones al dato de la imposibilidad de determinar la filiación conforme a la ley anterior.

En segundo lugar, sirve de ejemplo para ilustrar cómo un conflicto «internacional» puede verse involucrado con un conflicto «interno». Dado que la residencia del menor en Cataluña provoca la aplicación del Código Civil catalán con normas en esta materia, la SAP rebate la mal orientada pretensión de los demandantes al reclamar la aplicación del Derecho lituano, y va más allá al proponer la aplicación del Derecho civil catalán con fundamento en el art. 13.2 CC que acoge el principio de la territorialidad de los derechos. Desde ese subsistema la sentencia de instancia es revocable al no haber sido solicitada por el actor la impugnación de la filiación inscrita en el registro junto a la reclamación (art. 235-19 CCCat conforme al cual «La determinación de la filiación no tiene ningún tipo de efecto mientras exista otra contradictoria»), prescripción que respondiendo a la coherencia, no es tan evidente en el Derecho civil común.

4. Finalmente, el caso tiene interés en la medida en que sobre él se cierne la duda de si el demandante en instancia ocultaba una intención fraudulenta. Son varios los datos del sustrato fáctico - conocimiento por parte del actor del nacimiento del menor pero inacción hasta transcurridos seis años del nacimiento, falta de cumplimiento de obligaciones afectivas, o económicas, como tampoco ofrece asistencia económica o material con la interposición de la demanda en instancia, y sobre todo no consta residencia habitual en España alejando el supuesto de la posesión de estado- los que conducen a la AP a criticar la ausencia de intervención de un defensor judicial del menor. Esos mismos datos nos llevan a sospechar que el demandante buscaba tal vez por esta vía acogerse a alguno de los supuestos que posibilitan la residencia en España a nacionales de países terceros, es decir, dirigido a obtener la tarjeta de familiar de ciudadano de la Unión (conforme a los arts. 1, 2 y 4 del RD 240/2007, de 16 de febrero, sobre entrada, libre circulación y residencia en España de ciudadanos de los Estados miembros de la UE y de otros Estados parte en el Acuerdo sobre el Espacio Económico Europeo). Visto así es un excelente ejemplo de la relación de vasos comunicantes que ofrecen las normas reguladoras de los conflictos de leyes y el Derecho de Extranjería.

Mónica GuZMÁn ZAPATER

UNED

http://dx.doi.org/10.17103/redi.68.1.2016.3b.13

\subsection{Determinación de la ley aplicable: Versorgungsausgleich}

2016-14-Pr

DIVORCIO.-Ley aplicable.-Cónyuges de nacionalidad alemana residentes en España.-Derecho a percibir parte de la pensión de jubilación del marido (Versorgungsausgleich).-Calificación.

Preceptos aplicados: art. 3 del Reglamento 4/2009; art. 22.3 LOPJ; Convenio sobre la Ley aplicable a las obligaciones alimenticias hecho en La Haya el 2 de octubre de 1973; art. 9.2 CC; art. 1.587 del $B G B$ alemán.

Sentencia Audiencia Provincial de Barcelona (Sección 12. ${ }^{a}$ ), núm. 308/2015, de 12 de mayo. Ponente: Elena Farré Trepat.

\section{F.: Aranzadi Westlaw, JUR 2015/186407.}


El $\$ 1587$ del BGB alemán... regula una institución que no encuentra un paralelismo exacto en la legislación española —aunque en la sentencia de divorcio y en este procedimiento se haya asimilado a la pensión compensatoria-pues se orienta hacia el desequilibrio económico que se produce en el momento de la jubilación de los cónyuges, tomando en consideración las respectivas expectativas de cobro de una pensión de jubilación o de obtener una pensión procedente del servicio público de pensiones que han tenido ambas partes.

[...] una finalidad alejada del concepto de los alimentos como institución tendente a paliar las necesidades económicas más inmediatas del alimentista... no es abarcada por el R. 4/2009, debiendo quedar al margen de las normas del mismo. En este caso deberíamos acudir a la norma de conflicto prevista en el art. 9.2 CC conforme al cual los efectos del matrimonio se regirán por la ley personal común de los cónyuges al tiempo de contraerlo...

Nota. 1. La presente sentencia resuelve un recurso de apelación contra una sentencia de primera instancia sobre modificación de medidas acordadas en una anterior sentencia de divorcio dictada en 1996. Se había solicitado la reducción de un 75 por 100 de las cantidades a percibir por la esposa, en virtud de un cambio sustancial de la situación económica y problemas de salud del marido. Ambos cónyuges eran de nacionalidad alemana, si bien residían en el municipio barcelonés de Esplugues de Llobregat desde 1972.

2. El interés de la sentencia radica en que en la misma se plantean dificultades relativas a la calificación de las prestaciones económicas objeto de litigio. Se trataba del derecho a percibir una parte de las cantidades devengadas al esposo en concepto de pensión de jubilación, lo que conforme al Derecho alemán (§ 1587 BGB) se conoce como el Versorgungsausgleich. Tanto en la sentencia de divorcio, como con posterioridad, la participación de la esposa en la pensión de jubilación del marido se había asimilado a la pensión compensatoria del Derecho español. Sin embargo, la Audiencia Provincial señala, con razón, que el Versorgungsausgleich se orienta hacia el desequilibrio económico que se produce en el momento de jubilación de los cónyuges y no puede, por tanto, asimilarse a la prestación compensatoria.

3. La cuestión controvertida es la ley aplicable a dichas prestaciones dinerarias, que dependía de si se podían o no calificar como obligaciones de alimentos. La parte actora sostenía que era aplicable el Derecho español en virtud del Convenio de La Haya de 2 de octubre de 1993 (sic), mientras que la parte demandada consideraba aplicable el Derecho alemán y al respecto alegaba los arts. 9.2 y 107 CC así como al Reglamento 4/2009 del Consejo en materia de alimentos.

4. Si bien en ningún momento la sentencia comentada menciona el concepto de calificación, la magistrada ponente plantea muy correctamente los términos del debate. Analiza, teniendo en cuenta el Preámbulo del Reglamento 4/2009 (considerando 11) y la jurisprudencia del Tribunal de Justicia (Sentencia Farell/Long), el concepto de alimentos, partiendo de la premisa de que es un concepto autónomo que incluye a las pensiones compensatorias entre cónyuges, cuestión, por cierto, sobre la que podría haber dudas. En un primer momento, parece que se decanta por considerar que el concepto de alimentos es un concepto amplio que englobaría a las prestaciones dinerarias objeto de debate. Sin embargo, con posterioridad un análisis del contenido del Derecho alemán la lleva a poner en cuestión la operación realizada, pues señala que la finalidad de la institución alemana se aleja del concepto de alimentos como institución tendente a paliar las necesidades más inmediatas del alimentista, en tanto surte efectos a partir de la jubilación y, por consiguiente, se refiere al futuro. 
5. Se puede reprochar a la sentencia comentada que no se decante por una de las alternativas, incompatibles entre sí. Se concluye, en un primer momento, que es aplicable el Derecho alemán en virtud del art. 5 del Protocolo de alimentos, entendiendo que ha de excepcionarse la aplicación de la ley de la residencia habitual del acreedor de alimentos, pues la ley alemana tiene una relación más estrecha con el matrimonio. Para llegar a esta conclusión se manejan varios elementos, relacionados con el supuesto de hecho (cónyuges de nacionalidad alemana, celebración del matrimonio en Alemania y adopción de los hijos comunes en Alemania) así como relativos al iter procesal (divorcio conforme a la ley alemana y establecimiento de la obligación litigiosa conforme al Derecho alemán), siendo estos últimos los que en mi opinión acaban decantando la decisión. Conforme a la calificación alternativa se concluye asimismo que es aplicable el Derecho alemán en virtud del art. 9.2 CC (ley aplicable a los efectos del matrimonio). Por tanto, la Audiencia no se halla frente a la necesidad de decantarse por una u otra opción para la resolución del caso concreto.

6. En opinión de quien suscribe la calificación correcta es la segunda. La institución del Versorgungsausgleich del Derecho alemán no depende las necesidades de uno de los cónyuges, sino que tiene como finalidad compensar a aquel cónyuge (habitualmente la mujer), que, en virtud de una mayor dedicación al cuidado de los hijos y de la familia, ha tenido un menor desarrollo profesional, ha cotizado en menor medida a la Seguridad Social o adoptado menos medidas de ahorro para la vejez y, como consecuencia, percibe menores rentas dinerarias una vez transcurrida la edad laboral. La institución tiene finalidades distintas a las de la institución de alimentos y parecería forzado aplicar el Protocolo de La Haya de 2007.

Podría pensarse que se trata de una obligación subsumible en el régimen económico matrimonial y, de hecho, durante el proceso de negociación del Proyecto de Reglamento sobre la ley aplicable al régimen económico matrimonial su inclusión en el ámbito de aplicación del Reglamento se debatió ampliamente. Finalmente se optó por su exclusión, que se justifica en el considerando 12.a) de la última versión del texto cerrado en noviembre de 2014 haciendo referencia a la variedad de sistemas existentes en los Estados miembros.

7. En Alemania la cuestión de la calificación del Versorgungsausgleich no es tampoco pacífica. Tradicionalmente se había aplicado la ley rectora del divorcio, lo que en el momento actual implicaría la aplicación del Reglamento Roma III sobre la ley aplicable a la separación y el divorcio (RAUSCHER, T., Internationales Privatrecht, Heidelberg, 4. ${ }^{\text {a }}$ ed., 2012, p. 214). Desde el punto de vista de quien suscribe esta interpretación no se sostiene, pues el Reglamento se aplica únicamente a la disolución o relajación del vínculo matrimonial y no a sus efectos sobre el patrimonio de los esposos (considerando 10). El Reglamento Roma III nada dice acerca de los efectos personales del matrimonio y podría defenderse que estos se incluyen dentro del ámbito de aplicación del Reglamento. Pero incluso si así fuere resulta artificial considerar a un derecho de contenido esencialmente económico como un efecto personal del matrimonio.

8. Entiendo, por tanto, que acierta la Audiencia de Barcelona al aplicar a la materia el art. 9.2 CC. Lo único que posiblemente haya que lamentar es la ya citada ambigüedad de la sentencia y que no se haya aprovechado para plantear un recurso prejudicial respecto a una cuestión en la que son muchas las dudas. La exclusión de la ley aplicable al Versorgungsausgleich del ámbito de aplicación de las normas de conflicto europeas no deja, por otra parte, de ser incongruente y puede conducir a 
resultados diferentes, según donde se plantee la demanda. Ello parece incompatible con los objetivos de la cooperación civil.

\author{
Cristina GonZÁLEZ BeILFUSS \\ Universidad de Barcelona \\ http://dx.doi.org/10.17103/redi.68.1.2016.3b.14
}

\title{
3.3. Determinación de la ley aplicable: cesión de créditos
}

2016-15-Pr

CESIÓN DE CRÉDITOS.-Contratos de préstamo celebrados en Holanda.Contrato de cesión del crédito con base en los referidos contratos de préstamo sujeto al Derecho holandés.-Ley aplicable a la cesión de créditos.-Prueba del Derecho extranjero.

Preceptos aplicados: art. 10.5 CC; art. 4 Convenio de Roma de 19 de junio de 1980, aplicable a las obligaciones contractuales; art. 12.6 CC; art. 281 LEC.

Sentencia del TS, Sala de lo Civil, núm. 198/2015, de 17 de abril. Ponente: Rafael Saraza Jimena.

\section{F.: Aranzadi Westlaw, RJ 2015/1350.}

Los antecedentes de los recursos extraordinario por infracción procesal y de casación resueltos por la Sala 1. ${ }^{a}$ del Tribunal Supremo son los siguientes: Por el Juzgado de Primera Instancia núm. 7 de Figueres, con fecha 1 de septiembre de 2006, se dictó sentencia desestimando la demanda interpuesta por D. Alfonso Octavio, solidariamente contra Fluvia Parc, S. L. U., D. Jon Pelayo y D. ${ }^{a}$ Julia Guillerma, en reclamación de la cantidad de 1.311.912,99 euros, en concepto de principal, intereses ordinarios y de demora en virtud de dos contratos de préstamo suscritos en Holanda. Contra dicha Sentencia D. Alfonso Octavio interpuso recurso de apelación que fue admitido a trámite y se formuló oposición al mismo por la parte contraria. La Audiencia Provincial de Girona estimó el recurso de apelación, revocó la sentencia del Juzgado de Primera Instancia y estimó plenamente la demanda. D. ${ }^{a}$ Julia Guillerma, en su propio nombre y como sucesora procesal de la sociedad Fluvia Parc, S. L. U., y D. Jon Pelayo interponen contra la sentencia de la Audiencia Provincial recursos extraordinario por infracción procesal y de casación.

Nota. 1. Los hechos que dan lugar a esta sentencia fueron los siguientes: D. Alfonso Octavio interpuso demanda contra Fluvia Parc, S. L. U., D. Jon Pelayo y D. ${ }^{\text {a Ju- }}$ lia Guillerma Fluvia Parc, S. L. U., D. Jon Pelayo y D. . Julia Guillerma alegando ser cesionario del crédito que el cedente (D. Ricardo Gustavo) tenía contra los demandados en virtud de dos contratos de préstamo. Ambos préstamos fueron suscritos en Holanda. Con el dinero prestado los demandados adquirieron una serie de fincas en las que desarrollar un proyecto urbanístico en San Pere Pescador (Girona). Con posterioridad, suscribieron un contrato de cesión del crédito que el primero alegaba tener contra los demandados con base en los referidos contratos de préstamo, que sometieron al Derecho holandés. El proyecto inmobiliario no llegó a desarrollarse por los demandados. En la demanda se reclamaba 1.311.912,99 euros (431.000 euros de principal y 880.912,99 euros de intereses devengados). Consideraba aplicable el Derecho holandés y aportaba un documento notarial que recogía la regulación prevista en 
el Derecho holandés para las cuestiones suscitadas en la demanda. Los demandados se oponen y, entre otros argumentos, esgrimen que el Derecho aplicable no es el holandés, sino el español, por lo cual no se pueden calcular intereses sobre los intereses vencidos y los tipos de interés pactados hacen que la cláusula deba ser considerada nula por aplicación de la Ley española de Usura. El Juzgado de Primera Instancia desestimó la demanda porque estimó la falta de legitimación pasiva de los demandados, pues los mismos no habían intervenido en el negocio de cesión del crédito al efecto de prestar su consentimiento, por lo que no les era oponible. Como argumento de refuerzo, el Juzgado consideró que al existir en el documento de cesión del crédito una cláusula de sumisión expresa a los juzgados de s-Hertogenbosch, en los Países Bajos, y la sujeción del mismo a la legislación holandesa, eran competentes territorialmente los juzgados de dicha localidad holandesa. El demandante apeló la sentencia. La Audiencia Provincial estimó el recurso de apelación, revocó la sentencia del Juzgado de Primera Instancia y estimó plenamente la demanda. La Audiencia Provincial entendió que los demandados no habían alegado la falta de competencia internacional, por lo que los tribunales españoles eran competentes por existir una sumisión tácita de los demandados. Consideró que el Derecho aplicable era el holandés, por determinarlo así el art. 10.5 del Código Civil y el art. 4 del Convenio de Roma de 19 de junio de 1980, aplicable a las obligaciones contractuales. En el caso de la cesión del crédito, porque las partes se habían sometido expresamente al Derecho holandés. En el caso de los préstamos, porque se habían celebrado en Holanda.

2. Ley aplicable a la cesión de créditos. La parte recurrente, con una mescolanza de alegaciones, atinentes a cuestiones muy diversas, que infringe la exigencia de precisión y claridad propia del recurso de casación, plantea que el Derecho holandés ha sido aplicado incorrectamente. La sentencia de la Audiencia Provincial resulta imprecisa en lo que a la aplicación de las normas de conflicto que determinan la aplicación del Derecho holandés se refiere. En el caso que nos ocupa la Audiencia Provincial debió aplicar el Derecho holandés al contrato de cesión del crédito, no en virtud del art. 4 del CR sino del art. 3 (ley elegida por las partes). Además, resulta curioso el recurso al art. 10.5 CC (aplicación de la ley nacional común de los contratantes). Más que las partes se hubieren «sometido expresamente al Derecho holandés», fueron las mismas quienes eligieron de forma expresa a la totalidad del contrato de cesión del crédito el Derecho holandés. En el supuesto de que las partes no hubieran realizado tal elección, entonces sí, el art. 4 del CR hubiese sido de aplicación y nos hubiera llevado a la determinación como ley aplicable la de la residencia habitual del cedente del crédito (que es el prestador característico de este contrato). Entonces, quizá, el Derecho aplicable hubiera sido otro, pues del cedente solo conocemos su nacionalidad holandesa, pero nada se indica en la sentencia acerca de su residencia habitual.

3. Prueba del Derecho extranjero. Para abordar esta cuestión, el TS nos recuerda cuál es el régimen de prueba y de carga de la prueba del Derecho extranjero (véase comentario de CARRASCOSA GONZÁLEZ, J., "Breves reflexiones sobre la STS 17 abril 2015. Principio de adquisición procesal y prueba del Derecho extranjero y muchas cosas más", disponible en http://accursio.com/blog/? $p=288$ ) poniendo el acento en cinco cuestiones: i) el tribunal español debe aplicar de oficio las normas de conflicto del Derecho español (art. 12.6 CC), que pueden ser de origen interno, comunitario o convencional internacional; ii) como consecuencia lógica de que los jueces españoles no tienen obligación de conocer el Derecho extranjero, se ha exigido históricamente la prueba del mismo, de forma que en este extremo el Derecho recibe un tratamiento similar al que reciben los hechos, pues debe ser objeto de alegación y prueba, siendo necesario acreditar no solo la exacta entidad del Dere- 
cho vigente, sino también su alcance y autorizada interpretación (véase comentario de Rodríguez Pineau, E., en REDI, 1997-24-Pr); iii) si de acuerdo con la norma de conflicto española es aplicable el Derecho extranjero, la exigencia de prueba del mismo no transforma el Derecho extranjero, en cuanto conjunto de reglas para la solución de conflictos, en un simple hecho. Esto trae consigo varias consecuencias. La primera, que la infracción del Derecho extranjero aplicable para resolver las cuestiones objeto del proceso es apta para fundar un recurso de casación, por lo que las reglas de la carga de la prueba son normas procesales reguladoras de la sentencia y su infracción debe ser denunciada por el cauce del art. 469.1.2. ${ }^{\circ}$ de la Ley de Enjuiciamiento Civil. La segunda, que es la que aquí nos interesa, que el tribunal no queda constreñido, como en la prueba de hechos en los litigios sobre derechos disponibles, a estar al resultado de las pruebas propuestas por las partes, sino que puede valerse de cuantos medios de averiguación estime necesarios para su aplicación; iv) el empleo de los medios de averiguación del Derecho extranjero es una facultad, pero no una obligación del tribunal, y v) la consecuencia de la falta de prueba del Derecho extranjero no es la desestimación de la demanda, o la desestimación de la pretensión de la parte que lo invoca, sino la aplicación del Derecho español. Ahora bien, llama poderosamente la atención que el TS no haya valorado la posible contrariedad del Derecho holandés con el orden público español, que dé por buena la ley holandesa que avala intereses del 24 por 100 y del 31 por 100 y que no confronte esta ley extranjera con la ley española de Usura.

En definitiva, más sombras que luces nos deja esta sentencia. Por una parte, se trata de otra ocasión perdida: una vez más, el TS hace una incorrecta lectura de la doctrina del TC sobre la prueba del Derecho extranjero [véase ÁlvAREz GonZÁLEZ, S., «Aplicación judicial del Derecho extranjero: la desconcertante práctica judicial, los estériles esfuerzos doctrinales y la necesaria reforma legislativa», La Ley, año XXIV, núm. 6.287, de 4 de julio de 2005; GARAU SOBRINO, F., «La no-doctrina constitucional sobre la aplicación y prueba del Derecho extranjero», en Forner Delaygua, J. J., GonZÁlez BeIlfuss, C. y Viñas FARRe, R. (coords.), Entre Bruselas y La Haya. Liber amicorum Alegría Borrás, Madrid-Barcelona-Buenos Aires-São Paulo, Marcial Pons, 2013, pp. 429-443]. Por otra, es cuanto menos poco ejemplar observar la incorrecta aplicación de algunas fuentes de Derecho internacional privado español por parte de los Tribunales. En tercer lugar, resulta alarmante como los operadores jurídicos llamados a representar y defender los intereses de las partes siguen sin estar familiarizados con las fuentes de Derecho internacional privado español aplicables a un conflicto privado internacional como el que da lugar a la sentencia objeto de esta Nota.

Alfonso Ortega GimÉnez

Universidad Miguel Hernández de Elche http://dx.doi.org/10.17103/redi.68.1.2016.3b.15

\subsection{Determinación de la ley aplicable: sucesión por causa de muerte}

2016-16-Pr

LEY APLICABLE A LA SUCESIÓN POR CAUSA DE MUERTE.-Sucesión testamentaria.-Reenvío.-Condiciones para su aplicación: solución prevista por el art. 12.2 CC.—Solución aplicable según el Reglamento 650/2012.

Preceptos aplicados: arts. 9. 8 y 12.2 del CC. 
Sentencia AP Alicante (Sección 6. ${ }^{\text {a }}$ ), núm. 105/2015, de 27 de mayo. Ponente: José María Rives Seva.

\section{F.: Aranzadi Westlaw, JUR 2015/202046.}

[...] que siendo de aplicar la ley británica, nacionalidad del causante, existe libertad de testar, siendo intrascendente que se les declare o no herederos legítimos, por cuanto en nada afectaría a sus legítimas. Se trata la cuestión debatida de una mera interpretación jurídica acerca de la Ley aplicable, teniendo en cuenta que el causante era de nacionalidad británica (como es el caso que ahora nos ocupa) y en el Derecho inglés existe una libertad de testar absoluta no existiendo la institución de la legítima, cuestión esta, la del derecho extranjero, que se trata de una cuestión de hecho cuya existencia y vigencia no ha sido discutida por las partes en el procedimiento.

Dispone el artículo 9.1 del Código Civil que la ley personal correspondiente a las personas físicas es la determinada por su nacionalidad. Dicha ley regirá la capacidad y el estado civil, los derechos y deberes de familia y la sucesión por causa de muerte. En virtud de este precepto, como el padre de la demandante es de nacionalidad británica, su sucesión por causa de muerte se debe regir por el derecho inglés. Refuerza esta postura el mismo artículo 9.8: La sucesión por causa de muerte se regirá por la ley nacional del causante en el momento de su fallecimiento, cualesquiera que sean la naturaleza de los bienes y el país donde se encuentren.

[...] En el testamento otorgado en España por Don... en fecha..., y atendiendo a su ley nacional, la inglesa, se dice que instituye heredera universal de todos sus bienes, derechos y acciones en España, a su esposa Doña... Con el mismo no se está respetando la legítima de la hija que, por otra parte, no debe hacerlo por cuanto en el derecho inglés existe la total libertad de testar, pero la norma que rige la sucesión por causa de muerte en el derecho inglés escinde la sucesión hereditaria en dos regímenes jurídicos: la herencia de los bienes inmuebles estará sometida a la ley aplicable por razón de su situación, y la de los muebles será regulada por las normas de aplicación en el lugar donde el causante hubiere tenido su última residencia.

En el caso presente solamente se hace referencia al bien inmueble situado en España..., por lo que la sucesión se rige, en cuanto a las legítimas, por la remisión que se hace a la ley española. Y así nos encontramos con el artículo 12 del Código Civil, que en su núm. 1 dice que la calificación para determinar la norma de conflicto aplicable se hará siempre con arreglo a la ley española; y en su núm. 2, que la remisión al derecho extranjero se entenderá hecha a su ley material, sin tener en cuenta el reenví que sus normas de conflicto puedan hacer a otra ley que no sea la española...

Nota. 1. La sentencia comentada se pronuncia sobre el recurso interpuesto contra la resolución dictada por el Juzgado de Primera Instancia núm. 4 de Denia, de 16 de septiembre de 2014, la cual tiene un amplio contenido: por un lado, reconoce a dos hijos preteridos de un fallecido de nacionalidad británica y, en consecuencia, los efectos registrales de dicha filiación paterna. Por otro, reconoce la condición de herederos forzosos de estos hijos no instituidos como herederos por el fallecido. Y, por último, como efectos de dicho reconocimiento, declara la reducción de las instituciones de herederos y los legados ordenados por el finado, en el testamento otorgado ante notario español, así como la nulidad de cuantos actos, documentos y negocios jurídicos se opongan al contenido de dicha resolución judicial.

El fallo de primera instancia es recurrido por la esposa, junto a otra hija del causante - que antes tuvieron la condición de demandadas y no comparecieron, por lo 
que fueron declaradas en rebeldía procesal-, las cuales consideran que, siendo aplicable la ley británica, ley nacional del causante, y bajo la libertad de testar que la misma recoge, no se afectarían las legítimas de los hijos reconocidos con posterioridad al fallecimiento del padre. La AP de Alicante desestima el recurso y confirma íntegramente la Juzgado de Primera Instancia núm. 4 de Denia.

2. El caso que nos ocupa es bastante frecuente en la práctica procesal española: resolver la sucesión de un nacional británico que tiene como último domicilio el Estado español y que, mediante testamento, instituye como heredera universal de todos sus bienes, derechos y acciones localizados en España a su esposa (véase, sobre un supuesto que guarda gran similitud, Álvarez GonzÁlez, S., Nota a la STS, Sala de lo Civil, Sección 1. ${ }^{\mathrm{a}}$, de 12 de enero de 2013, REDI, 2015, pp. 235-238).

Tanto los datos de hecho como los fundamentos jurídicos del caso hacen referencia a un tema clásico de DIPr: el reenvío en materia sucesoria. Y dado que se trata de un procedimiento respecto a un causante fallecido antes de la fecha de efectiva aplicación del Reglamento 650/2012, de 4 de julio, relativo a la competencia, la ley aplicable, el reconocimiento y la ejecución de las resoluciones, a la aceptación y la ejecución de los documentos públicos en materia de sucesiones mortis causa y a la creación de un certificado sucesorio europeo (DOUE, L 201, de 27 de julio de 2012, en adelante, Reglamento 650/2012), las normas aplicadas corresponden a nuestro DIPr interno, arts. 9.8 y $12.2 \mathrm{CC}$, que, de manera recurrente, la AP de Alicante interpreta y aplica en coherencia con otras sentencias adoptadas por esta misma sección (véanse por todas, SSAP 124/2003, de 10 de marzo; 282/2012, de 28 de mayo, y 498/2012, de 31 de octubre).

3. Así pues la Audiencia retoma el análisis de las condiciones de aplicación del art. 9.8 CC y, atendiendo a que el punto de conexión sitúa la solución en el Derecho inglés y tiene en cuenta que el mismo divide el derecho aplicable a la sucesión hereditaria según se trate de bienes muebles o inmuebles. En el caso que nos ocupa solo se hace referencia a bienes inmuebles situados en España, cosa que no se discute. Por tanto, la herencia estará sometida a ley aplicable por razón de su situación: la ley española del CC y esta con clara protección de las legítimas. De este modo, el reenvío no fragmenta el derecho aplicable a la sucesión y mantiene la unidad de la ley aplicable, cuestión en la que jurisprudencia es unánime y la AP sigue la misma dirección (véanse, por todas, SSTS de 15 de noviembre de 1996 y de 23 de septiembre de 2002, SAP Murcia, de 13 de noviembre de 2011, SAP de Granada de 19 de julio de 2004 y SAP de Asturias de 1 de septiembre de 2005).

4. Para finalizar, conviene hacer una breve referencia al impacto que tendría en un supuesto como este la aplicación del Reglamento 650/2012. Si situamos temporalmente este procedimiento con posterioridad al 17 de agosto de 2015, el resultado sería exactamente el contrario al que nos conduce el CC: la aplicación de la ley inglesa. En efecto, en el presente caso el causante eligió mediante disposición mortis causa la ley inglesa - ley del Estado de su nacionalidad-, con lo que tal elección es válida de acuerdo con el art. 22 Reglamento 650/2012. Y no cabría el reenvío, ya que, aunque el Reino Unido deba ser considerado Estado tercero a efectos del Reglamento, su art. 34.2 excluye expresamente el reenvío en el supuesto de que la aplicación de la ley venga determinada por una elección de ley.

Lerdys S. HEREdia SÁNCHEZ Universidad de Alicante http://dx.doi.org/10.17103/redi.68.1.2016.3b.16 
2016-17-Pr

DERECHOS REALES.-Problema de calificación.-Reconocimiento testamentario de un derecho real.-Derecho real sobre bienes inmuebles.-Bienes inmuebles sitos en España.-Aplicación de la ley española.

Preceptos aplicados: arts. 10.1 y 12.1 CC; y art. 4.2 RRI.

Sentencia del Tribunal Supremo, Sala de lo Civil (Sección 1. a), núm. 342/2015, de 23 de junio. Ponente: Francisco Javier Orduña Moreno.

\section{F.: Aranzadi Westlaw, RJ 2015/4484.}

En este contexto, la interpretación de la citada cláusula cuarta del testamento, conforme a la voluntad declarada por el testador, no ofrece duda al respecto pues nos encontramos ante un claro reconocimiento del derecho alegado por la parte demandante. En efecto, solo en este sentido puede interpretarse el reconocimiento fiduciario que el testador realiza sobre la titularidad dominical de los inmuebles adquiridos con anterioridad a su matrimonio, declarando que "no son suyos únicamente» por haberlos adquirido conjuntamente con capital de todos ellos (madre y hermanos). Este reconocimiento del derecho de los demandantes, que no se integra en la naturaleza y alcance de las disposiciones testamentarias, resulta clave para la determinación de la norma de conflicto aplicable que vira, necesariamente, del artículo 9.8 del Código Civil y, por ende, de la ley nacional del causante (Derecho hebreo), hacia el artículo 10.1 del citado Cuerpo legal y, por tanto, a la ley territorial donde se hallen los bienes inmuebles en cuestión, esto es, la legislación española.

Idéntica conclusión se obtiene si se interpreta, como también resulta posible, el citado reconocimiento del derecho en el plano obligacional derivado de un reconocimiento de deuda (artículo 10.5 del Código Civil), en donde la remisión al Reglamento "Roma I» (CE - Núm. 593/2008) conduce, por aplicación analógica, a la ley del país donde el deudor tenga la residencia habitual (artículo 4.2 de dicho Reglamento).

Nota. 1. La STS objeto del presente comentario casa una decisión de la AP de Madrid que tuvimos ocasión de anotar en esta misma revista [REDI, LXVI (20142 ), pp. 280-285], haciendo hincapié en sus graves deficiencias técnicas. Una fugaz mirada retrospectiva al caso permite ponerse en antecedentes: habiéndose requerido por parte de los beneficiarios del testamento otorgado por un ciudadano marroquí de confesión judía el cumplimiento de una cláusula testamentaria que les era favorable, el juez, en primera instancia, desestima la demanda por la falta de prueba del Derecho extranjero aplicable, siendo este veredicto confirmado en apelación, luego de descartar la audiencia el recurso al Derecho español, bien a título subsidiario, bien a consecuencia de la intervención de correctivos funcionales como el reenvío de retorno o la excepción de orden público.

2. De manera sorprendente, el TS aborda el litigio bajo una nueva perspectiva, la de la calificación, que en ningún momento había asomado en el razonamiento de los tribunales inferiores. Manifiesta la sentencia al respecto que «la determinación de la concreta norma de conflicto exige un previo proceso de interpretación de las categorías o conceptos jurídicos incardinados en el supuesto de hecho a considerar. En nuestro sistema, por aplicación del art. 12.1 del Código Civil esta calificación que encierra la interpretación conceptual del supuesto de hecho se realiza de acuerdo a 
lo dispuesto en la ley española». Dicho esto, en esencia correcto, el TS no está tan acertado en el párrafo siguiente de su exposición, cuando añade que, «[e]n el presente caso, de acuerdo con la cuestión debatida, resulta imprescindible entrar en el análisis de la naturaleza y del alcance que realmente presenta la cláusula cuarta del referido testamento, pues del resultado del mismo va a depender la determinación de la norma de conflicto que va a dirimir la normativa objeto de aplicación». Consecuente con este planteamiento, el Alto Tribunal apela al contraste entre el contenido típico y el contenido atípico del testamento para justificar el desplazamiento de la controversia desde el terreno sucesorio, en el que lo habían ubicado los juzgadores precedentes, hasta el ámbito de los derechos reales —o, incluso, de los derechos de crédito- que es la opción calificatoria por la que se decanta el TS al afirmar que «la interpretación de la citada cláusula cuarta del testamento [...] no ofrece duda al respecto, pues nos encontramos ante un claro reconocimiento del derecho alegado por la parte demandante». El principal reproche que puede hacerse a esta línea argumental es que no atiende debidamente a una de las claves del asunto: el «objeto de la calificación». Para los especialistas, no es ningún secreto la dificultad de la cuestión y la diversidad de opiniones que suscita (para un compendio de las mismas, véase KROPHOLLER, J., Internationales Privatrecht einschließlich der Grundbegriffe des Internationalen Zivilverfahrensrechts, 6. ${ }^{a}$ ed., Tübingen, Mohr Siebeck, 2006, pp. 117-121), pero la publicación de importantes estudios [paradigmático: ANCEL, B., "L'objet de la qualification», JDI, 107 (1980), pp. 227-268] ha contribuido a arrojar luz sobre la misma. Entre nosotros, quien ha sentado con extrema lucidez las premisas para una adecuada comprensión del problema ha sido Álvarez González, S. [«Artículo 12, apartado 1», en AlbaladeJo, M. y Díaz Alabart, S. (dir.), Comentarios al Código civil y compilaciones forales, t. I, vol. 2, Artículos 8 a 16 del Código Civil, 2. a ed., Madrid, Edersa, 1995, pp. 874-877], al que seguimos cuando concluye que el objeto de la calificación lo constituye el binomio integrado por las pretensiones de las partes y su fundamentación $-\mathrm{O}$, al menos, su contextualización-, de suerte que la falta de uno de estos dos componentes imposibilita la identificación de la norma de conflicto a la que ha de acudir el juez para determinar el Derecho aplicable (p. 875). Lo que se acaba de exponer no concuerda con el modo de proceder del TS a la hora de calificar, como pasamos a desarrollar.

3. Acogiendo el motivo de casación aducido por los recurrentes —el de que «la resolución impugnada interpretó erróneamente el suplico del escrito de demanda»-, el TS corrige este defecto desplazando el foco de su interpretación de las pretensiones de los actores - que deja en un segundo plano- a la disposición mortis causa en las que aquellas se asientan. Es evidente que, al obrar así, el Alto Tribunal centra su atención en la realidad jurídica (la cláusula testamentaria) que sirve de fundamento a la solicitud de los demandantes, relegando el examen del tenor de esa solicitud. Si una calificación correcta exige una evaluación conjunta - y simultánea- de lo que se pide y sobre qué base se pide, el hecho de prescindir en gran medida del primer elemento de la ecuación no puede conducir más que a un resultado deficiente, como se constata en el litigio que nos concierne. Efectivamente, a partir de la ambigua cláusula en cuestión, en la que el causante "[d]eclara que los bienes inmuebles que figuran actualmente como suyos propios e inscritos a su nombre en el Registro de la Propiedad respectivo, con fecha anterior a su matrimonio, no son suyos únicamente, sino la nuda propiedad de todos ellos y el veinte por ciento del usufructo de los mismos, pues el ochenta por ciento del usufructo de dichos bienes corresponde a partes iguales y proindiviso a su madre [...] y a sus hermanos [...], por haberlos adquirido conjuntamente con capital de todos ellos y en la proporción y forma dichas, por lo que para evitar toda clase de dudas lega a su madre [...] y a sus hermanos [...], por partes 
iguales y proindiviso, el usufructo vitalicio del ochenta por ciento», se abrían ante los destinatarios de la misma varias fórmulas - sustantivas y procesales- de reclamación, sin embargo, en el petitum de su demanda, aquellos solicitan al tribunal que «[i]nterprete la cláusula 4. ${ }^{\text {a }}$ en el sentido de que: A) Declare que la cláusula $4 .^{a}$ supone el legado del $80 \%$ del usufructo de los inmuebles a los que se refiere la cláusula, en pago de una deuda contraída con los legatarios, conforme el artículo 873 del Código Civil. B) Subsidiariamente, declare que la cláusula 4. ${ }^{a}$ supone un reconocimiento de deuda a favor de su madre y los hermanos [del causante] y que ese reconocimiento se concreta en el resultado de la valoración del $80 \%$ del usufructo de los inmuebles a los que se refiere la cláusula calculado a la fecha de adquisición de la propiedad de los inmuebles respecto al valor actual de los mismos, y, subsidiariamente, declare el legado a favor de la madre y los hermanos [del causante] del $80 \%$ del usufructo de los inmuebles a los que se refiere la cláusula. C) Subsidiariamente, declare que la cláusula 4. ${ }^{\mathrm{a}}$ supone el reconocimiento de un derecho a favor de la madre y los hermanos [del causante] del $80 \%$ del usufructo de los inmuebles a los que se refiere la cláusula desde la fecha de adquisición de la propiedad de los mismos, con todo ello que por derecho les corresponda, y, subsidiariamente, declare el legado a favor de la madre y los hermanos [del causante] del $80 \%$ del usufructo de los inmuebles a los que se refiere la cláusula. D) Subsidiariamente, declare el legado a favor de la madre y los hermanos [del causante] del 80\% del usufructo de los inmuebles a los que se refiere la cláusula». Cabría entrar a discutir las bondades de la fundamentación y articulación del suplico, pero de lo que no hay duda es de que en él se recogen las pretensiones de los actores que el TS no puede soslayar con el argumento, esgrimido por estos al recurrir, de su interpretación errónea por parte de los órganos jurisdiccionales inferiores. Primero, porque no es verdad, pues tanto en la primera instancia como en la segunda se califica correctamente la cuestión jurídica — principal— como de índole sucesoria. Segundo, porque, aun cuando se hubiera producido una equivocación previa en dicha caracterización, el Alto Tribunal estaba obligado, de querer enmendarla, a hacerlo ajustándose al papel que, en la operación de calificación, le incumbe al juez, y que el TS no parece tener claro.

4. En un proceso civil como el español, inspirado en el principio de justicia rogada, es indiscutible que, al dirigirse a los tribunales en busca de tutela jurisdiccional, es el demandante el que, por medio de la pretensión - fundamentada o contextualizada-que les formula, fija el «objeto del proceso» —esto es, aquello sobre lo que va a versar el litigio-; noción que, para lo que aquí interesa, puede equipararse a la de «objeto de la calificación» (BATIFFOL, H. y LAGARDE, P., Traité de droit international privé, t. I, 8. ${ }^{a}$ ed., Paris, LGDJ, 1993, p. 477). Por tanto, es el actor el que, al concretar su solicitud y la justificación de la misma, determina tanto el objeto del litigio como el de la calificación. Ahora bien, este «poder» del demandante no quita que sea únicamente al juez a quien competa realizar propiamente la calificación, pues la que hubiere efectuado aquel al enunciar su pretensión no vale más que para informar jurídicamente al tribunal (BATIFFol, H. y LAGARDE, P., ibid.), sin vincularle en absoluto. En el caso que nos ocupa, el TS diluye este reparto de funciones, ya que no solo lleva cabo la calificación de lo que se le pide, sino que, excediéndose en sus atribuciones, altera la petición misma; circunstancia que se llega a plantear por las características del suplico de la demanda, que incorpora un cúmulo subsidiario de acciones $-\mathrm{o}$ pretensiones-. Estas hipótesis, que reciben el nombre de acumulaciones eventuales o subsidiarias se admiten en nuestro Derecho siempre que las peticiones «se ha[ga]n constar por su orden y separadamente» (art. 399.5 LEC), "con expresión de la acción principal y de aquella otra u otras que [se] ejercita[n] para el solo evento de que la principal no 
se estime fundada» (art. 71.4 LEC). En ellas, el demandante jerarquiza con esmero sus pretensiones, porque «le interesa y solicita sobre todo obtener una tutela jurídica concreta (la que solicita en primer lugar), y solo en el caso de que se le deniegue dicha tutela, pide el otorgamiento de la solicitada en segundo lugar» [TAPIA FERNÁNDEZ, I., "Artículo 71 », en Cordón Moreno, F. et al. (coords.), Comentarios a la Ley de Enjuiciamiento Civil, vol. I, Arts. 1 a 516, 2. ${ }^{a}$ ed., Cizur Menor, Aranzadi, 2011, p. 611]. El orden de preferencia establecido por el actor en el petitum de su demanda es, como resulta obvio, de gran trascendencia, puesto que la primera pretensión, adjetivada de "principal» (art. 73.1.1. ${ }^{\circ}$ LEC; sobre las «acumuladas», véanse las reflexiones de GAScóN INCHAUSTI, F., La acumulación de acciones y de procesos en el proceso civil, Madrid, La Ley, 2000, pp. 28-30), es la que, además de servir para sustentar la competencia judicial internacional de nuestros tribunales (¿hubiera tenido el TS la misma percepción del pleito si, domiciliado el difunto en España, los inmuebles litigiosos radicaran en Marruecos?), integra el objeto de la calificación en tanto que dicha pretensión no haya sido desestimada. A fin de actuar correctamente, el Alto Tribunal tenía que haberse limitado a categorizar la petición primordial de los actores (la reclamación del legado de deuda ordenado por el causante en su testamento), que, con toda probabilidad, le hubiera merecido - al igual que al juez de instancia y a la audiencia- una calificación sucesoria; y, solamente después de haber rechazado esta pretensión, hubiera podido el TS descender gradualmente los restantes escalones del suplico para, de modo idéntico, ir sometiendo cada una de las solicitudes de los demandantes al veredicto de su estimación o desestimación. Sin embargo, la Sala de lo Civil no lo hace así, sino que, pretextando una supuesta mala interpretación del petitum por parte de los tribunales inferiores - en realidad, una crítica al enfoque de la parte actora-, dedica sus esfuerzos a otras pretensiones contenidas en el mismo - la tercera (reconocimiento de un derecho real) y la segunda (reconocimiento de una deuda), ipor este orden!- - que, en su opinión, reflejan más fielmente la voluntad del de cuius expresada en la cláusula testamentaria controvertida. El corolario de este proceder calificatorio del TS es el recurso al art. 10.1 CC y, parece que defectivamente, al art. 4.2 RRI (aunque, para una obligación reconocida en un testamento otorgado en diciembre de 1975, debería haberse invocado el art. $10.5 \mathrm{CC}$ ); normas de conflicto, ambas, que conducen a la aplicación del Derecho material español. A la postre, la sentencia transmite la impresión de que, al tratarse de un litigio relativo a bienes inmuebles sitos en España, la principal preocupación de nuestro más Alto Tribunal era la de acabar observando la ley del foro, lo cual podía haberse logrado, sin tantos juegos malabares, apelando resignadamente a su competencia residual en ausencia de prueba del Derecho extranjero.

$$
\begin{array}{r}
\text { Josep M. Fontanellas MorelL* } \\
\text { Universidad de Lleida } \\
\text { http://dx.doi.org/10.17103/redi.68.1.2016.3b.17 }
\end{array}
$$

2016-18-Pr

SUCESIÓN POR CAUSA DE MUERTE Y TRUST.—Sucesión intestada.-Ley aplicable a la sucesión.-Trust constituido por el causante.-Bienes aportados al trust como parte de la herencia.-Nulidad de los actos del trustee.-Extinción y disolución del trust.-Competencia exclusiva de los tribunales de Jersey.-Litispendencia internacional.-_Inhibición a favor del tribunal inglés.—Ley inglesa aplicable al trust.

* Esta colaboración se inserta en el Proyecto de investigación MINECO DER2012-36920 y en el Grupo de investigación consolidado de la Generalitat de Catalunya 2014SGR483. 
Preceptos aplicados: art. 9.8 CC; Convenio de La Haya de 1985, sobre la ley aplicable al trust y a su reconocimiento; arts. 5.6, 23.4, 27 y 60.3 del Reglamento 44/2001.

Sentencia AP Granada (Sección 3. a), núm. 202/2015, de 30 de junio. Ponente: José Requena Paredes.

\section{F.: Aranzadi Westlaw, JUR 2015/223196.}

El segundo motivo, atinente al fondo, cuestiona la aplicación de la ley española cuando no es la aplicable a la sucesión, por ser la italiana conforme a las normas de conflicto de nuestro Código Civil (art. 9.8) y respecto al trust la aplicación de la ley inglesa de la Isla de Jersey como domicilio del mismo, así como el carácter vinculante, que ahora se alega también "ex novo", al margen de la escueta contestación a la demanda del Convenio de La Haya de 1980 [...] que, a diferencia del Reino de España, se dice que sí en el recurso fue ratificado por el Estado Italiano [...], pero con las matizaciones de irrelevancia por afectar a bienes y sociedades afincadas en España que se expresan en ese escrito.

Dicho de otro modo, la sentencia apelada sigue la secuencia y la Doctrina expuesta por nuestro Tribunal Supremo (Sala 1. ${ }^{\text {) }}$ de 30 de abril de 2008, que poco tiene que ver con los hechos enjuiciados en este procedimiento cuya compleja estructura jurídica se simplificaba por los actores, por un lado, a una mera cuestión sucesoria de igualdad de cuotas hereditarias entre herederos legítimos de igual derecho [...] y por otro a eliminar el trust del debate, ignorarlo porque nuestro ordenamiento nacional no lo reconoce y entender que las 13 fincas aportadas a Agreste no son de la sociedad sino del causante y como tal deben heredarse por todos los hijos en igualdad.

[...] No es solo que por la ley de la Isla de Jersey sobre fideicomisos (trust) de 1984 se rija el mismo por la ley de esa Corte y territorio (arts. 3 a 5), sino que la normativa comunitaria, Reglamento núm. 44/2001 [...] en su artículo 5.6 señala que las personas con domicilio en un estado miembro podrán ser demandadas, tratándose de un trust, si tienen la "condición de fundador, trustee o beneficiario de un trust constituido ya en aplicación de la ley, ya por escrito o por un acuerdo verbal confirmado por escrito, ante los tribunales del Estado miembro en cuyo territorio estuviere domiciliado el trust», lo que, enlazado con las reglas de la litispendencia del propio Reglamento, también podía determinar la inhibición a favor del Tribunal inglés que conoció de la propuesta de venta y división [...]

Así las cosas, cualquiera que sea la decisión final en el ámbito del trust [...], desconociendo si alcanzó firmeza aquella sentencia, no compete a este Tribunal corregir las decisiones de otro Tribunal ni [...] anular el proceso inglés al que, además, las propias partes se sometieron a la vista de la Sentencia de 14 de mayo de 2014 [...].

Nota. 1. Esta sentencia permite comentar un supuesto que pone de manifiesto las dificultades que han de afrontar nuestros tribunales cuando tienen que abordar conflictos en los que interviene una institución como el trust, desconocida en nuestro ordenamiento jurídico, en el ámbito sucesorio. La sentencia trae causa de un procedimiento iniciado en primera instancia en el que se solicitaba por los demandados: a) la declaración de su condición de herederos forzosos del causante, un ciudadano de nacionalidad italiana que falleció intestado en el año 2005; $b$ ) la inclusión en la herencia yacente de los bienes aportados por el causante a un trust en el año 1995 del que eran beneficiarios, además de los demandantes — hijos de su segundo matrimonio- otros hermanos de vínculo sencillo - hijos de su primer matrimonio-, y c) la declaración de nulidad de los actos del trustee que pudiesen perjudicar los derechos de los deman- 
dados como herederos forzosos. Simultáneamente a la demanda se plantearon medidas cautelares con el fin de impedir actos de disposición al trustee o terceros sobre los bienes que integraban el trust. Si bien en primera instancia se estimó íntegramente el petitum planteado por la parte demandada la decisión fue recurrida en apelación ante la Audiencia Provincial de Granada que revocó la misma.

A mi juicio, tres son los aspectos que han de ser objeto de comentario en esta sentencia: en primer lugar, la distinción entre la sucesión hereditaria y la institución del trust (inter vivos, pues se había constituido y entrado en vigor en vida del causante) que nos permita afirmar que el patrimonio aportado al trust no forma parte del caudal hereditario del causante; en segundo lugar la determinación de los tribunales competentes para conocer de ambas cuestiones y, finalmente, la ley aplicable tanto a la sucesión cuanto al trust.

2. En relación con los bienes aportados al trust y su posible consideración como patrimonio del causante hay que afirmar que el trust constituye un patrimonio diferente y diferenciado y, consecuentemente, los bienes aportados al mismo durante la vida del causante no formarán parte de su herencia yacente en el momento del fallecimiento.

La Audiencia critica la errónea decisión del tribunal de instancia al considerar que los bienes del trust deben integrarse en la herencia yacente y, para ello, se refiere a la doctrina de nuestro TS y a la ausencia de un debate jurídico adecuado en esta materia. Sin embargo, pasa de puntillas y no se pronuncia sobre esta cuestión que, en mi opinión, está relacionada con la ley aplicable a sendas instituciones: de una parte, la ley italiana aplicable a la sucesión - ley nacional del causante en el momento del fallecimiento (art. 9.8 del CC) — y, de otra, la ley inglesa aplicable al trust - ley determinada por el causante (settlor) en el momento de su constitución o, en su defecto, la del país con el que presente el vínculo más estrecho (Convenio de La Haya sobre la ley aplicable al trust y a su reconocimiento).

Pues bien, aun cuando el causante dispone de libertad para establecer un trust inter vivos, en cuyo caso los bienes aportados al mismo no pasarán a formar parte de su herencia yacente, resulta esencial considerar si en el momento de constituir el trust respetó los derechos de legítima de sus hijos previstos en la ley italiana aplicable a su sucesión. Considerando que los beneficiarios del trust eran todos sus hijos, herederos legítimos y titulares con los mismos porcentajes - a excepción de una hermana- y que la finalidad del mismo era evitar los impuestos sucesorios en España podría concluirse que no afecta a los derechos legitimarios de sus hijos si bien se trata de una cuestión que desconocemos.

3. Por el contrario, la sentencia sí aborda la acción de nulidad de futuro planteada en relación con los actos de disposición del trustee con la finalidad de preservar los bienes aportados por el causante al trust, desarrollando, así, los aspectos relacionados con la competencia judicial internacional.

Si bien los jueces y tribunales españoles no pueden dejar de resolver aquellos supuestos en los que intervenga la institución del trust considero que, tal y como plantea la Sala, en el pronunciamiento de primera instancia se produce una incorrecta aplicación de las normas de competencia judicial internacional. Esta circunstancia solamente puede entenderse, aunque no justificarse, por el desconocimiento de la institución del trust en nuestro ordenamiento jurídico lo que conduce en ocasiones a nuestros tribunales a ignorarla en lugar de buscar posibles soluciones coherentes con nuestro Derecho. Resulta pues evidente la confusión que genera la sentencia de ins- 
tancia al decidir sobre una acción de nulidad de futuro - los actos dispositivos del trustee- sobre la que no resultan competentes los tribunales españoles considerando que, en ausencia de prórroga de la competencia, el trustee puede ser demandado «...ante los tribunales del Estado miembro en cuyo territorio estuviere domiciliado el trust» (arts. 23.4 y 5.6 del Reglamento 44/2001), es decir, ante los tribunales de la isla de Jersey.

En este sentido, procede recordar que la extinción y disolución del trust y el posterior reparto entre sus beneficiarios se había planteado con anterioridad ante los tribunales de Jersey, siendo autorizada por el mencionado tribunal mediante sentencia de fecha 14 de mayo de 2014. De este modo, parece obvio que la posterior demanda ante el tribunal de primera instancia español tenía por objeto, al socaire de la determinación del caudal hereditario del causante, la declaración de nulidad de los actos del trustee sobre el patrimonio del trust, cuestión que ya había sido objeto de litigio ante el Tribunal de Jersey.

La Sala, por su parte, manifiesta que es inviable solicitar la nulidad de los actos del trustee sin traer al proceso a los verdaderos titulares afectados por esa nulidad. Sin embargo, al tratarse de una demanda con el mismo objeto, causa e identidad de partes ha de operar el instituto de la litispendencia y el tribunal de primera instancia debió inhibirse a favor del tribunal de Jersey que ya se había declarado competente en relación a la disolución y liquidación del trust (art. 27.2 del Reglamento 44/2001). De otro modo, se asumía por el juzgado de instancia un litigio incompatible e irreconciliable con el que paralelamente se seguía ante los tribunales de Jersey.

4. Finalmente, por lo que respecta a la ley aplicable, en la sentencia de instancia se produce una errónea determinación de la ley aplicable a ambas instituciones. En relación al trust resultaría de aplicación la ley inglesa si esta hubiese sido la elegida por el constituyente (settlor), cuestión que desconocemos. En su defecto, sería de aplicación la ley con la que el trust se encuentre más estrechamente vinculado (arts. 6 y 7 del Convenio de La Haya). En este sentido, si bien los bienes que forman parte del trust se encuentran localizados en España hemos de considerar aplicable la ley inglesa en virtud del domicilio (isla de Jersey) del trust. La Sala así lo reconoce, teniendo en cuenta que el tribunal de Jersey ya había resuelto la extinción y resolución del trust con arreglo a la ley inglesa (art. 8 del Convenio de La Haya) y así, aunque de manera implícita, reconoce la errónea decisión del tribunal de instancia que declaraba la nulidad de los acuerdos y actos de disposición del trustee, entre ellos, la extinción y distribución de los bienes del trust, con arreglo a la ley española.

Raúl LAFUENTE SÁNCHEZ

Universidad de Alicante

http://dx.doi.org/10.17103/redi.68.1.2016.3b.18 